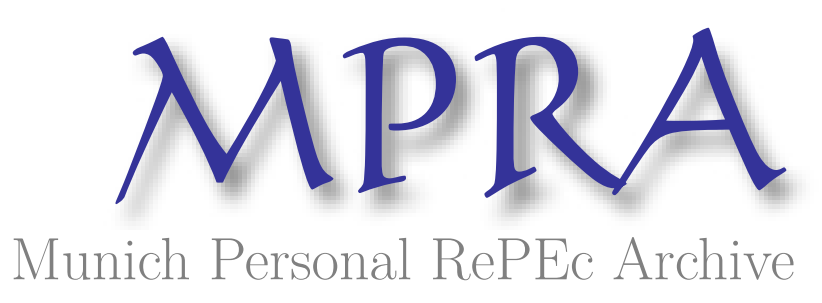

\title{
Estimating Auctions with Externalities: The Case of USFS Timber Auctions
}

Kuehn, Joseph

CSU East Bay

June 2016

Online at https://mpra.ub.uni-muenchen.de/74775/

MPRA Paper No. 74775, posted 28 Oct 2016 11:43 UTC 


\title{
Estimating Auctions with Externalities: The Case of USFS Timber Auctions *
}

\author{
Joseph Kuehn ${ }^{\dagger}$
}

June 16, 2016

\begin{abstract}
This paper studies how bidding strategies and auction outcomes are affected by downstream competition, particularly for USFS timber auctions. This is done by extending the auction estimation literature to a model where outside competition affects bidding behavior in that bidders are then not only concerned with whether they win the auction, but also the identity of the winner if it is not them. Applying the estimation technique to the case of timber auctions, I find that downstream competition in the lumber industry affects the bidding behavior of mill bidders, sometimes leading to the misallocation of timber tracts.
\end{abstract}

Keywords: auction with externalities, auction estimation, timber auctions

JEL Classification: D44, L13, L40, L73

\section{Introduction}

In many auction settings, competition between bidders outside the auction can affect bidding strategies and auction outcomes, as bidders are not only concerned with whether they win the auction, but also the identity of the winner if it is not them. For example if bidders are firms that later compete in a downstream market, then letting a rival obtain the auctioned object can lead to profit losses downstream. Accounting for this downstream competition introduces new incentives for bidding beyond just acquiring the object, in that bidders will try to keep the object away from certain rivals, and will incorporate that into their bid strategy. The effect of outside competition on a bidder is referred to as an externality of the auction, which comes from the auctions with externalities models of Jehiel, Moldovanu, and Stacchetti (1996) and Jehiel, Moldovanu, and Stacchetti (1999).

\footnotetext{
*I would like to thank Connan Snider, Hugo Hopenhayn, Rosa Matzkin, Masanori Tsuruoka, Robert Zeithammer, and conference participants at the 2016 IIOC for useful comments and suggestions. I would also like to thank Phil Haile for providing the data used in this paper on his website. All errors are my own.

${ }^{\dagger}$ Department of Economics, CSU East Bay, joseph.kuehn@csueastbay.edu
} 
An important recent example of an auction setting where outside competition may play a role, is the U.S Forest Service timber auctions. In the 2007 U.S. Supreme Court case of Weyerhaeuser Company vs. Ross-Simmons Hardwood Lumber Company, the plaintiff, Ross-Simmons, accused Weyerhaeuser of predatory bidding in timber auctions to keep timber away from Ross-Simmons and other lumber competitors, in order to achieve monopoly power in the downstream lumber market. One of the points of contention in the case was to what degree was Weyerhaeuser bidding higher on sawlogs in order to keep the timber away from other sawmill competitors.

The goal of this paper is to look at how downstream competition in the lumber industry affected bidding strategies in timber auctions and affected those auction outcomes, as was alleged in the above case. I do so by extending the structural auction estimation methods of Guerre, Perrigne, and Vuong (2000). The typical auction model does not in general allow for additional outside competition between bidders to affect strategies and outcomes, and a key feature of such an auction environment is that bidders care about who the object is allocated to even if it is not them. Thus bidding strategies will not just depend on the number of competitors a bidder faces, but also the identities of those competitors. Therefore I extend the typical auction model by introducing an identity dependent negative payoff called the negative externality, which bidders incur if they lose the auction to a particular rival. I show that the negative externalities and distributions of valuations in such a model can be identified from observations on bids and bidder identities.

I then apply this estimation strategy to USFS timber auctions to identify the degree to which timber auction bids are driven by bidders' own valuations for the tract compared to their desire to keep the tract away from rival firms. Distinguishing between the two motives is important when asking questions about market participation, object allocation, bidder subsidies, bidder collusion, and auction design. Identifying the externality effect is also useful when thinking about whether or not the incentives exist for timber auction bidders to engage in predatory bidding as was alleged in the Supreme Court case against Weyerhaeuser.

Beyond timber auctions, this type of auction model also applies to many other auction settings as well. One can think of instances in mergers and acquisitions, where the potential buyers care not only about the benefits from acquiring or merging with the target firm, but also the potential losses through decreased market share or increased relative costs, if their rival instead acquires the target. This is common in industries with vertical integration where competitors who do not vertically integrate first may be pushed out of the market. As Jehiel, Moldovanu, and Stacchetti (1996) noted this setting also encompasses the exclusive sale of inputs to downstream competitors (such as a patent or the early exclusivity deal between Apple and AT\&T) and the awarding of important projects that have large effects on the industry (such as the awarding of government contracts in the aerospace industry). This 
model could also be used to explore the contracting of athletes in professional sports. In such a setting teams are known to pay too high a price for certain athletes in an attempt to prevent their rival from getting the player. This overbidding could be a result of teams considering the negative externality of being beat by their rival if the player goes to the opposing team, in addition to the benefits of having that player on their own team.

The model I use is based on that of Jehiel, Moldovanu, and Stacchetti (1996). In addition to the private values that bidders receive upon winning the auction object, losing bidders will suffer negative externalities that depend on both the type of the winner and the sufferer. This model differs from other auction models estimated in the literature, in that losing bidders will be affected differently depending on the particular externality value between themselves and the winner of the auction, which are ostensibly based on the degree of rivalry between the two bidders outside the auction. As a result bidders care who wins the auction if they do not.

I will show that both the externality parameters, as well as the value distributions, can be identified and estimated in this model from observations on auctions that include the bids and the identities of the auction participants. The identification strategy depends on observing enough variation in the set of participating bidders. As bidders of a given type face varying sets of competitors who confer differing levels of externalities upon the bidder, this will shift their observed bid strategies. By making the important assumption that observed bidder participation is exogenously determined, I can then identify the negative externality parameters from how bids fluctuate with the types of competitors a bidder faces.

I implement this strategy by first estimating bidder valuations as a function of the externality parameters. I then search for the parameter values that lead to bidder valuation distributions that are the same for bidders of the same type, across auctions with different sets of competing bidders. I introduce three different estimators that each employ this strategy by finding parameters that match different features of the value distribution across auctions with varying bidder sets. I also show that this identification and estimation strategy can be extended to the case where the externality depends on the acquirer's valuation in a parameterized way ${ }^{1}$, and the case when there are only observations on the winning bid and the participating bidders' types.

I then apply this estimation strategy to the case of USFS timber auctions to see if downstream competition has a significant effect on timber auction bidding as was alleged in the U.S. Supreme Court case of Weyerhaeuser Company vs. Ross-Simmons Hardwood Lumber Company. To my knowledge, no prior work has looked at the effect downstream competition has had on timber auction outcomes. I find that downstream competition between mill bidders ${ }^{2}$ is sufficient enough that a mill bidder acquiring

\footnotetext{
${ }^{1}$ This is the case that is the most similar to the original model of Jehiel, Moldovanu, and Stacchetti (1996), where externalities are private information for the bidder and are allowed to be correlated with private valuations.

${ }^{2}$ Mill bidders are defined separately from logger bidders, where mills have manufacturing capacity and loggers do
} 
the timber tract will cost a rival mill bidder by between $10 \%-18 \%$ of the heterogeneous portion of their valuation for the timber. This has important consequences in this application because it indicates that mill bids are generally higher than the bids of logger companies not because of a stochastic dominance in their valuations for timber tracts, but instead because rival mills compete more heavily with one another in the downstream lumber market compared to the downstream competition between other types of bidding firms. Downstream competition can also affect the allocation of the timber if the firms that win the auctions are not those firms that value the timber tract the most, but are instead those firms that bid high in order to keep the tract away from rivals. I find that this is true for $4.2 \%$ of the auctions in my sample, where the presence of externalities leads the timber tract to be misallocated to a bidder that does not have the highest valuation for the tract.

As stated above, the model used in this paper is based on the auctions with externalities models from the prior literature, originating with Jehiel, Moldovanu, and Stacchetti (1996) and Jehiel, Molodovanu, and Stacchetti (1999). Both papers were interested in characterizing revenue maximizing mechanisms in a setting where a $N \times(N-1)$ matrix $A$ contained the externalities, $\alpha_{i j}$, that player $j$ received when player $i$ won the object. Other papers that followed with similar models include Jehiel and Moldovanu (1996), Jehiel and Moldovanu (2000), and das Varma (2002). Jehiel and Moldovanu (1996) look at externalities' effects on bidder participation, and Jehiel and Moldovanu (2000) models externalities in a standard second price-auction to look at the effects of reserve prices and entry fees on revenue. In das Varma (2002), the author analyzes bidding behavior in an open ascending bid auction with externalities that are restricted to only come from one other bidder, and to have a fixed value. These models are also similar to auction models that incorporate spite incentives such as those of Morgan, Reis, and Steiglitz (2003), Levine (1998), and Brandt, Sandholm, and Shoham (2007). My model draws on the characteristics of the models used in these papers to answer a new question about how empirically do negative externalities due to downstream competition, affect bidding behavior and outcomes.

The estimation techniques in this paper are based on the structural auction estimation literature originating with Guerre, Perrigne, and Vuong (2000), and extended by many others including Li, Perrigne, and Vuong (2002). The identification and estimation strategy of this paper is closest to that of Haile, Hong, and Shum (2003), and Guerre, Perrigne, and Vuong (2009), which both exploit variation in bidder sets for identification. The former uses this variation to test whether valuations are private or common value in a first-price sealed bid auction, while the later uses bidder set variation to identify risk aversion in first-price auctions. In this paper I use variation in bidder sets to identify the value of the negative externalities based on how observed bid strategies fluctuate with the number and identities of competitors.

not. This is the same classification used by Athey, Levin, and Seira (2011). 
This paper is also related to those that estimate asymmetric auctions such as Campo, Perrigne, and Vuong (2003) and Flambard and Perrigne (2006). Both papers use techniques similar to that of Guerre, Perrigne, and Vuong (2000) to estimate an asymmetric first price auction, with the former considering affiliated private values, while in the later valuations are independent. For my paper, in addition to potential asymmetries in bidders' value distributions, there is asymmetry in bidding strategies caused by the type-dependent negative externalities. Thus even in a setting where valuations are distributed symmetrically, bid strategies will be asymmetric due to the differing influence of the negative externalities.

There is also a related literature that looks at how bids are linked between sequential highway procurement auctions. This includes Balat (2013), Groeger (2014), Jeziorski and Krasnokutskaya (2014), and Jofre-Bonet and Pesendorfer (2014). In this dynamic setting, bids are influenced by outcomes in previous auctions. This is similar to my auction model where bids are affected by competition outside the current auction, but the key difference is I look at externalities due to competition between rival bidders, while in the sequential procurement auction literature a bidder's externality is derived from how they themselves performed in a previous auction.

Finally this paper is related to the literature on timber auctions. Athey, Levin, and Seira (2011) analyze the differences between open and sealed bid auctions for USFS timber, Baldwin, Marshall, and Richard (1997) test the timber auctions for collusion, and Haile (2001) looks at the effects of resale on bidder valuations. Aradillas-Lopez, Gandhi, and Quint (2013) use the timber auctions to study identification in ascending correlated private value auctions, Lu and Perrigne (2008) use the auctions to estimate bidder risk aversion, and Haile, Hong, and Shum (2003) test between common and private values in timber auctions. This paper differs from those in that I focus on how competition in the downstream lumber market affects auction bidding and outcomes.

The rest of the paper is organized as follows. Section 2 presents the model and the equilibrium bidding strategies. Section 3 discusses the identification and estimation strategy for the the distribution of bidder valuations and the externality parameters, as well as some extensions, including the case when only the winning bid is observed. Section 4 presents the results from a Monte Carlo experiment of the estimators, and section 5 applies these techniques to USFS timber auctions to see how downstream competition affects bidding behavior in that setting. Section 6 concludes the paper.

\section{Model}

The model is an auction consisting of $n \geq 2$ risk-neutral bidders competing for one indivisible object. The set of bidders is denoted by $\mathbb{B}$. Bidders are partitioned into $K$ groups based on the bidders' types $k$ in the downstream market. There is no restriction on the number of types $K$. In the 
application I separate bidders into three types following Athey, Levin, and Seira (2011): mills that have manufacturing capacity, loggers that do not, and small businesses. The set of bidders of type $k$ is denoted by $\mathbb{B}_{k}$ (where $\bigcup_{k=1}^{K} \mathbb{B}_{k}=\mathbb{B}$ and $\bigcap_{k=1}^{K} \mathbb{B}_{k}=\emptyset$ ), and the number of bidders of type $k$ is denoted by $n_{k}$ (where $n_{1}+\cdots+n_{K}=n$ ). The auction mechanism is a first price auction where each bidder $i_{k}$ submits a bid $b_{i_{k}}$, and the bidder with the largest bid gets the object and pays a price equal to the bid they submitted.

Each bidder, $i_{k} \in \mathbb{B}_{k}$, has a valuation for the object, $v_{i_{k}}$, drawn independently from the distribution, $F_{k}(\cdot)$. Valuation $v_{i_{k}}$ is assumed to be private information to bidder $i_{k}$. Each $F_{k}(\cdot)$ has support $\left[\underline{v_{k}}, \overline{v_{k}}\right]$ and is common knowledge to all bidders. The distributions $F_{k}(\cdot)$ may be the same for all $k$ in which case we say that bidders have symmetric valuations, or they may be different for bidders of different types $k$ in which case we say that bidder valuations are asymmetric.

In addition to each bidder having a valuation for the object, which is their payoff if they win the auction, losing bidders will suffer a negative payoff that will depend on their identity and the identity of the winning bidder. This negative payoff a bidder receives from losing is called the negative externality, and it is denoted by $\alpha_{i_{k}, j_{k^{\prime}}}$, where $j_{k^{\prime}}$ is the winning bidder and $i_{k}$ is the sufferer of the externality. Thus the gross payoff for each bidder $i_{k} \in \mathbb{B}_{k}$ is as follows:

$$
\begin{cases}v_{i_{k}} & \text { if } i_{k} \text { wins } \\ -\alpha_{i_{k}, j_{k^{\prime}}} & \text { if } j_{k^{\prime}} \neq i_{k} \in \mathbb{B}_{k^{\prime}} \text { wins }\end{cases}
$$

The externality value, $\alpha_{i_{k}, j_{k^{\prime}}}$, represents the lost profit to bidder $i_{k}$ from bidder $j_{k^{\prime}}$ winning the auction object, ostensibly due to downstream competition between the two bidders. ${ }^{3}$ The online appendix contains examples of different models of downstream competition that fit with the above auction model. Because the size of the negative payoff a bidder receives depends on the identity of the winner, bidders will then care about who wins the object if they don't. Thus bidding strategies will take into account the incentive for certain bidders to bid in order to keep the object away from a rival, not just to win the object for themselves. This is what separates this auction model with externalities from a standard auction model without them.

For identification and estimation of the model I will assume that the value the negative externality $\left(\alpha_{i_{k}, j_{k^{\prime}}}\right)$ takes on, depends on both the type of the imposing bidder $\left(k^{\prime}\right)$ and the type of the receiving bidder $(k)$, and is a parameter of the model, $\alpha_{k, k^{\prime}}$. A model that is closer to that of Jehiel, Moldovanu, and Stachetti (1999), where bidder types are multidimensional, would have the externality values be private information to their imposer and be drawn from a common-knowledge pair-type distribution,

\footnotetext{
${ }^{3}$ The focus of this paper is on negative externalities $\left(\alpha_{i_{k}, j_{k^{\prime}}} \geq 0\right)$ rather than positive externalities. A model where the auction externalities are positive is associated with a different set of issues, such as whether firms will "free ride" by not participating in the auction.
} 
$F_{\alpha_{k, k^{\prime}}}$, that depends on both the type of the imposer of the negative payoff and the receiver. Due to the uncertainty that a bidder then has about the negative payoff they will receive if they lose to a particular rival, then under the assumption that private valuations are uncorrelated with the negative externalities, bidding strategies and the observed bid data from such a model would be equivalent to that of the model I assume where externalities are type-dependent parameters.

In the model with multi-dimensional bidder types, each bidder's bid strategy will depend on their valuation for the object, the bidder set they face, and their expectation about their negative payoff if they lose to a particular rival $j_{k^{\prime}}$, which is given by $E\left[\alpha_{i_{k}, j_{k^{\prime}}}\right]=\alpha_{k k^{\prime}}$. Since bid strategies only depend on the means of these distributions, nonparametrically identifying the externality distributions, or even identifying their variance in such a model, is not possible from bid data, since bid strategies are not going to depend on the variance of these distributions if bidders are assumed to be risk neutral. Therefore all that can be recovered from observations on bids is the means of these distributions, or the parameters, $\alpha_{k k^{\prime}}$. These can equivalently be recovered using the model that I assume where externalities are known parameters that depend on the types of both the imposer and receiver of the negative payoff.

Relaxing the independence between private valuations and the externalities, as is done in Jehiel, Moldovanu, and Stacchetti (1996), also makes sense in a variety of settings. The identification and estimation strategy of this paper can also be extended to that case when a particular form of the correlation between a bidder's private valuation for the object and the negative payoff they inflict upon other bidders when they win, is imposed. In this case externalities are identity-dependent and private information to the imposer. I show in Section 6 how such a model can still be identified and estimated using the strategy employed in this paper.

Identification and estimation of the model also initially assumes that bidder participation is exogenous. The exogeneity of bidder participation is important for estimation since I will be using variation in the bidder set for identification. This is an assumption and strategy that has been made in a number of structural auction estimation papers including Aradillas-Lopez, Gandhi, and Quint (2013), Guerre, Perrigne, and Vuong (2009), Haile, Hong, and Shum (2003), and Gillen (2010). ${ }^{4}$ The approach I use can also be adapted to several models of endogenous participation as was done in Haile, Hong, and Shum (2003). ${ }^{5}$ For example there could be some cost to entering the auction that restricts bidder entry. ${ }^{6}$ One thing to note when adapting those models of endogenous participation to the current setup with externalities, is that it is often reasonable to assume that bidders can't just

\footnotetext{
${ }^{4}$ Aradillas-Lopez, Gandhi, and Qunit (2013) assume exogenous participation to get bounds on seller revenue in ascending correlated private values auctions, while Guerre, Perrigne, and Vuong (2009) use it nonparametrically identify risk-aversion in first-price auctions. Haile, Hong, and Shum (2003) make the assumption to test between common and private values, and Gillen (2010) uses the assumption for identification in a level-k auction model.

${ }^{5}$ The reader is referred to Haile, Hong, and Shum (2003) for details on those extensions.

${ }^{6}$ Athey, Levin, and Seira (2011) provide such a model for the case of USFS timber auctions.
} 
avoid the negative externality by not participating in the auction. ${ }^{7}$ Thus an implicit assumption of any model of endogenous participation must be that bidders that are not observed to participate in the auction, but do compete in the downstream market, are assumed to have such a low combination of valuation draw and externality parameter that they don't meet the entry threshold (i.e. it is too costly for them to enter). In the application I do not model entry explicitly, but do allow for auction participation to be determined endogenously by unobserved auction heterogeneity.

What separates this model from other models of auctions, is that the degree of competition between the bidders outside of the auction, affects their payoffs in the auction. In the application to USFS timber auctions, competition between mills and loggers in the downstream lumber market affects how those firms bid in auctions for the key input of logs. Auction outcomes can have important implications on competition in the downstream market as evidenced by the antitrust case brought against Weyerhaeuser Company, and thus this competition should be an important determinant of bidding decisions, that is mostly ignored in other auction models. Beyond the application to timber auctions, there are also many other settings where such a model is appropriate. Examples include auctions for spectrum licenses, government contracts, and landing slots at an airport, as well as bidding in firm mergers and acquisitions. In these settings firms will bid more competitively against certain rivals in the auction, if they compete heavily against those rivals in the downstream market. Thus the structure of competition in the out of auction market will affect the auction results. In the Appendix I lay out three motivating examples of different models of market competition that could lead to the above auction model with externalities.

\subsection{Equilibrium}

The expected utility of bidder $i_{k} \in \mathbb{B}_{k}$ with valuation $v_{i_{k}}$, given that they submit bid $b$, is given by:

$$
u_{k}\left(v_{i_{k}}, b\right)=\left(v_{i_{k}}-b\right) \operatorname{Pr}\left(b \geq b_{l}, \forall l \in \mathbb{B}_{-i_{k}}\right)-\sum_{k^{\prime}} \alpha_{k k^{\prime}}\left[\sum_{j_{k^{\prime}} \neq i_{k} \in \mathbb{B}_{k^{\prime}}} \operatorname{Pr}\left(b_{j_{k^{\prime}}} \geq b_{l}, \forall l \in \mathbb{B}_{-j_{k^{\prime}}} \mid b\right)\right]
$$

where $\alpha_{k k^{\prime}}$ is the negative payoff a bidder of type $k^{\prime}$ imposes upon a bidder of type $k$ when the bidder of type $k^{\prime}$ wins the auction. At the Bayesian Nash equilibrium, each bidder chooses their bid in order to maximize expected utility given their valuation for the object. I restrict attention to symmetric equilibria by assuming each bidder of type $k$ follows the same strategy.

It can be shown that the above auction model satisfies conditions along the lines of McAdams

\footnotetext{
${ }^{7}$ For example in the timber auction application, this assumes that just because a bidder is not participating in the auction, doesn't mean they are not affected by how that auction outcome affects downstream competition in their market.
} 
(2003), for the existence of an equilibrium with monotone pure-strategy bidding functions. ${ }^{8}$ Thus I focus on equilibrium strategies that are differentiable and strictly increasing over a range of valuations. This range of valuations will be any valuation over a certain threshold that depends on both the bidder's type and the competition they are facing in the auction. One can think of bids above this threshold as equivalent to the notion of serious bids in Reny and Zamir (2004). The reason I only have monotone bidding strategies above this threshold is that with asymmetric bidders and externalities, bidders with valuations below this threshold will be indifferent between a continuum of lower bids, which all give them the same expected utility.

Establishing a unique equilibrium is difficult in general and is further complicated by the presence of externalities. With externalities, an auction participant's bid depends on their belief about who will get the object if they don't. This belief is endogenously determined in equilibrium, and so one can imagine that several sets of consistent beliefs could be constructed that are consistent with an equilibrium. In the absence of a uniqueness result, I make the additional assumption in the estimation below that all the observations on bids come from auctions where bidders use the same equilibrium strategy.

I am then interested in defining the monotone bidding function for all valuations above the indifference threshold. Let $\beta_{k}(\cdot)$ be the strictly increasing equilibrium bid strategy for a type- $k$ bidder, with an inverse denoted by $\beta_{k}^{-1}(\cdot)$. A bidder $i_{k} \in \mathbb{B}_{k}$ solves:

$$
\begin{aligned}
& \max _{b}\left\{\left(v_{i_{k}}-b\right)\left(\prod_{k^{\prime}} F_{k^{\prime}}\left(\beta_{k^{\prime}}^{-1}(b)\right)^{\left(n_{k^{\prime}}-\mathbf{1}\left\{k^{\prime}=k\right\}\right)}\right)\right. \\
& \left.-\sum_{k^{\prime}}\left[\alpha_{k k^{\prime}}\left(n_{k^{\prime}}-\mathbf{1}\left\{k^{\prime}=k\right\}\right) \int_{\beta_{k^{\prime}}^{-1}(b)}^{\overline{v_{k^{\prime}}}} \prod_{k^{\prime \prime}} F_{k^{\prime \prime}}\left(\beta_{k^{\prime \prime}}^{-1}\left(\beta_{k^{\prime}}(x)\right)\right)^{\left(n_{k^{\prime \prime}}-\mathbf{1}\left\{k^{\prime \prime}=k^{\prime}\right\}-\mathbf{1}\left\{k^{\prime \prime}=k\right\}\right)} f_{k^{\prime}}(x) d x\right]\right\}
\end{aligned}
$$

where $\mathbf{1}\{\cdot\}$ is the indicator function. Differentiating (2) with respect to $b$ for all $k$ will give a system of $K$ first order differential equations:

$$
\sum_{k^{\prime}}\left[\left(v_{i_{k}}-b+\alpha_{k k^{\prime}}\right)\left(\frac{\left(n_{k^{\prime}}-\mathbf{1}\left\{k^{\prime}=k\right\}\right) f_{k^{\prime}}\left(\beta_{k^{\prime}}^{-1}(b)\right) \beta_{k^{\prime}}^{-1^{\prime}}(b)}{F_{k^{\prime}}\left(\beta_{k^{\prime}}^{-1}(b)\right)}\right)\right]=1
$$

This system of equations, along with the boundary conditions at the indifference thresholds discussed above, define the equilibrium strategies $\beta_{k}(\cdot)$. Under certain assumptions on the model primitives, it may be possible to solve the system of differential equations for the equilibrium strategies $\beta_{k}(\cdot)$. More generally the system of equations is quite complicated, and will be difficult to solve even with the use of numerical methods. Thus I suggest a technique along the lines of Guerre, Perrigne, and Vuong (2000), that does not require solving directly for these equilibrium bidding strategies.

\footnotetext{
${ }^{8}$ McAdams (2003) derives conditions for the existence of a monotone pure strategy equilibrium for the case of multiunit auctions, but the setup of that paper can apply to the auction with externalities model of this paper, to establish the existence of an equilibrium with monotone bidding functions.
} 
Let $H_{k}(b \mid \mathbb{B})$ be the probability that a particular bidder $i_{k}$ of type $k$ wins the auction with a bid of $b$ given that the set of bidders is $\mathbb{B}$ (i.e. $H_{k}(b \mid \mathbb{B})=\operatorname{Pr}\left(\max _{j \in B_{-i_{k}}} b_{j} \leq b \mid \mathbb{B}\right)$ ). Then using the strict monotonicity of the bidding functions, I can write the expected utility of a type $k$ bidder as:

$$
u_{k}\left(v_{i_{k}}, b ; \mathbb{B}\right)=\left(v_{i_{k}}-b\right) H_{k}(b \mid \mathbb{B})-\sum_{k^{\prime}}\left[\alpha_{k k^{\prime}}\left(n_{k^{\prime}}-\mathbf{1}\left\{k^{\prime}=k\right\}\right) \int_{\underline{b_{k^{\prime}}(\mathbb{B})}}^{\overline{b_{k^{\prime}}(\mathbb{B})}} H_{k^{\prime}}\left(x \mid b_{i_{k}}=b, \mathbb{B}\right) g_{k^{\prime}}(x \mid \mathbb{B}) \mathrm{d} x\right]
$$

where $H_{k^{\prime}}\left(x \mid b_{i_{k}}=b, \mathbb{B}\right)$ is the probability that a specific bidder of type $k^{\prime}$ wins the auction with a bid of $x$ given that $i_{k}$ submits a bid of $b, g_{k^{\prime}}(x \mid \mathbb{B})$ is the bid density for a bidder of type $k^{\prime}$ given set

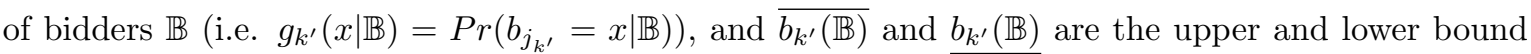
respectively, of the bid distribution for a bidder of type $k^{\prime}$ given set of bidders $\mathbb{B}$. The first order condition of this expected utility with respect to $b$ is:

$\left(v_{i_{k}}-b\right) H_{k}^{\prime}(b \mid \mathbb{B})=H_{k}(b \mid \mathbb{B})+\sum_{k^{\prime}}\left[\alpha_{k k^{\prime}}\left(n_{k^{\prime}}-\mathbf{1}\left\{k^{\prime}=k\right\}\right) \frac{\partial}{\partial b}\left(\int_{\underline{b_{k^{\prime}}(\mathbb{B})}}^{\overline{b_{k^{\prime}}(\mathbb{B})}} H_{k^{\prime}}\left(x \mid b_{i_{k}}=b, \mathbb{B}\right) g_{k^{\prime}}(x \mid \mathbb{B}) \mathrm{d} x\right)\right]$

The key to getting a tractable expression for the last term of equation (5) is to look at how $i_{k}$ 's bid $b$, enters the integral. The integral gives the probability that a specific bidder of type $k^{\prime}, j_{k^{\prime}}$, wins the auction given that $i_{k}$ bids $b$. This probability is only affected by $b$ in that for any $j_{k^{\prime}}$ bid of $x<b$, that probability of winning is 0 . For all rival bids of $x>b$, the probability of $j_{k^{\prime}}$ winning is the probability that all other bidders, excluding $j_{k^{\prime}}$ and $i_{k}$ (since it is already known that $i_{k}$ bids $b$ ), bid below $x$. This later probability is independent of $i_{k}$ 's bid of $b$. Thus we can simplify the above expression to an integral where $b$ only enters in the limit of integration as can be seen in equation (6). The derivation of this equality can be found in the Appendix:

$$
\int_{\underline{b_{k^{\prime}}(\mathbb{B})}}^{\overline{b_{k^{\prime}}(\mathbb{B})}} H_{k^{\prime}}\left(x \mid b_{i_{k}}=b, \mathbb{B}\right) g_{k^{\prime}}(x \mid \mathbb{B}) \mathrm{d} x=\int_{b}^{\overline{b_{k^{\prime}}(\mathbb{B B})}} \operatorname{Pr}\left(\max _{l \neq i_{k}, j_{k^{\prime}} \in B} b_{l} \leq x \mid \mathbb{B}\right) g_{k^{\prime}}(x \mid \mathbb{B}) \mathrm{d} x
$$

Now when I take the derivative with respect to bid $b$ I will get a tractable expression:

$$
\frac{\partial}{\partial b}\left(\int_{\underline{b_{k^{\prime}}(\mathbb{B})}}^{\overline{b_{k^{\prime}}(\mathbb{B})}} H_{k^{\prime}}\left(x \mid b_{i_{k}}=b, \mathbb{B}\right) g_{k^{\prime}}(x \mid \mathbb{B}) \mathrm{d} x\right)=-\operatorname{Pr}\left(\max _{l \neq i_{k}, j_{k^{\prime}} \in B} b_{l} \leq b \mid \mathbb{B}\right) g_{k^{\prime}}(b \mid \mathbb{B})
$$

Substituting this into equation (4) results in:

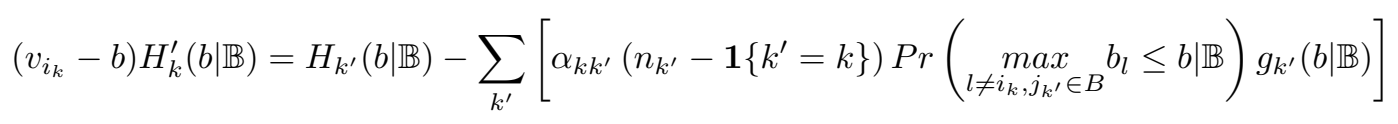


Rearrange and I get:

$$
v_{i_{k}}=b+\frac{H_{k}(b \mid \mathbb{B})}{H_{k}^{\prime}(b \mid \mathbb{B})}-\sum_{k^{\prime}}\left[\alpha_{k k^{\prime}}\left(n_{k^{\prime}}-\mathbf{1}\left\{k^{\prime}=k\right\}\right) \frac{\operatorname{Pr}\left(\max _{l \neq i_{k}, j_{k^{\prime}} \in B} b_{l} \leq b \mid \mathbb{B}\right) g_{k^{\prime}}(b \mid \mathbb{B})}{H_{k}^{\prime}(b \mid \mathbb{B})}\right]
$$

Equation (9) is a necessary condition for $b$ to be an optimal bid for a bidder of type $k$ with valuation $v_{i_{k}}$. This equation is very similar to the usual equation found in the structural auction estimation literature, but with a term added to the end. The extra term on the end of equation (9) is the increase in the bid over the standard equilibrium bid due to presence of rivals that can exert externalities on

the bidder. The term $\frac{\operatorname{Pr}\left(\max _{l \neq i_{k}, j_{k^{\prime}} \in B^{\prime}} b_{l} \leq b \mid \mathbb{B}\right) g_{k^{\prime}}(b \mid \mathbb{B})}{H_{k}^{\prime}(b \mid \mathbb{B})}$ can be interpreted as the probability that for the interested bidder, one of their rivals, $j_{k^{\prime}}$, bids $b$ and all other players in the auction have bid below $b$, so that the only way the interested bidder can prevent rival $j_{k^{\prime}}$ from obtaining the good, is to bid $b$ or marginally better. The parameter $\alpha_{k k^{\prime}}$ is the cost to $i_{k}$ of $j_{k^{\prime}}$ getting the object and so together the last term in equation (9) is the increase in expected utility the interested bidder receives from preventing rival $j_{k^{\prime}}$ from getting the object by making a bid of $b$.

Equation (9) will form the basis for the estimation strategy used in this paper. I will use it to get bidder valuations as a function of observed bids and externality parameters, $\left\{\alpha_{k k^{\prime}}\right\}_{k, k^{\prime}}$. Then in a similar fashion to that of Haile, Hong, and Shum (2003), I will use observed variation in bidder set $\mathbb{B}$, which leads to variation in the components of equation (9), to then identify and estimate the externality parameters.

\section{Identification and Estimation Strategy}

\subsection{Identification}

The goal of identification is to identify the set of externality parameters, $\left\{\alpha_{k k^{\prime}}\right\}_{k, k^{\prime}}$, and the distributions of valuations, $\left\{F_{k}\right\}_{k}$, from observations on bids and bidder identities from a sample of auctions, using the equilibrium equation (9). Assume that a series of $\mathrm{T}$ independent auctions are observed for the same object, and for each auction one observes the set of bidders $\mathbb{B}^{t}$, and the joint distribution of bids denoted by $G\left(b_{1}^{t}, \ldots, b_{n}^{t} \mid \mathbb{B}^{t}\right)$. I assume that there are $L$ externality parameters, $\alpha_{k k^{\prime}}$, to estimate, and that $\alpha$ is a $L \times 1$ vector of these parameters that belongs to the set $\mathbb{A} \subset \mathbb{R}^{L}$. With no restrictions on symmetry between externalities, then $L=K^{2}$, but by imposing some form of symmetry on the parameters, $L$ can be lowered, thus easing the requirements for identification. Asymmetries between bidder distributions, $F_{k}(\cdot)$, for bidders of different types, are also allowed. I say that $\alpha$ is identified if for any $\alpha^{*}, \tilde{\alpha} \in \mathbb{A}$ and any $F_{v^{*}}(\cdot), F_{\tilde{v}}(\cdot) \in \Im$, where $\Im$ is the set of strictly increasing and continuous 
distributions, if when $G\left(\cdot ; \alpha^{*}, F_{v^{*}}(\cdot) \mid \mathbb{B}\right)=G\left(\cdot ; \tilde{\alpha}, F_{\tilde{v}}(\cdot) \mid \mathbb{B}\right)$, for all observed bidder sets $\mathbb{B}$, it must be that $\alpha^{*}=\tilde{\alpha}$ and $F_{v^{*}}(\cdot)=F_{\tilde{v}}(\cdot)$.

The strategy behind identification will be similar to the strategies of Haile, Hong, and Shum (2003) and Guerre, Perrigne, and Vuong (2009), where I will use observed variation in the sets of bidders to identify the externality parameters. The idea is that bidders of a given type will bid differently depending on the number and identities of their opposing bidders. For example, say a mill bidder is in a timber auction competing with two other bidders for a timber tract. If both opponents are loggers, then the mill bidder will bid differently then if they were instead facing one logger and one other mill or two loggers, because of the different degrees of competition between bidders of different types.If the econometrician can observe a bidder of a particular type's bidding strategy in auctions with different sets of opponents, then he or she can make inference on what the value of the externality parameter must have been (i.e. the degree of competition between the auction opponents in the downstream market), given the observed difference in bidding strategies. Thus identification depends on observing enough variation in the sets of bidders, to be able to attribute the variation in bidding strategies to a particular externality value between bidder types.

Formally the first step for identification is to identify bidder valuations as a function of observed bids and the bidder set, and the unknown externality parameters. Equilibrium bidding equation (9) does this:

$v_{i_{k}}(\mathbb{B})=\xi_{k}(b, G ; \alpha, \mathbb{B})=b+\frac{H_{k}(b \mid \mathbb{B})}{H_{k}^{\prime}(b \mid \mathbb{B})}-\sum_{k^{\prime}}\left[\alpha_{k k^{\prime}}\left(n_{k^{\prime}}-\mathbf{1}\left\{k^{\prime}=k\right\}\right) \frac{\operatorname{Pr}\left(\max _{l \neq i_{k}, j_{k^{\prime}} \in B} b_{l} \leq b \mid \mathbb{B}\right) g_{k^{\prime}}(b \mid \mathbb{B})}{H_{k}^{\prime}(b \mid \mathbb{B})}\right]$

where $H_{k}(\cdot \mid \mathbb{B}), H_{k}^{\prime}(\cdot \mid \mathbb{B}), \operatorname{Pr}\left(\max _{l \neq i_{k}, j_{k^{\prime}} \in B} b_{l} \leq \cdot \mid \mathbb{B}\right)$, and $g_{k^{\prime}}(\cdot \mid \mathbb{B})$ are all known from the observed joint distribution of bids, $G(\cdot \mid \mathbb{B})$. Thus bidder valuations are identified as a linear function of the externality parameters.

Assuming that bidder participation is exogenous ${ }^{9}$, the distribution of valuations does not depend on the bidder sets $\mathbb{B}$, and so the distributions of valuations for a given bidder type will be equal across all auctions with different sets of bidders. Observed variation in these sets will result in a series of equalities between distributions of valuations that are functions of the externality parameters. Let $G$ be the observed distribution of bids when the bidder set is $\mathbb{B}$, and $G^{a}$ be the observed distribution of bids when the bidder set is some alternative $\mathbb{B}^{a}$. Then these identifying equalities can be written out as:

$$
F_{\xi_{k}}\left(\xi_{k}(b, G ; \alpha, \mathbb{B}) \mid \mathbb{B}\right)=F_{\xi_{k}}\left(\xi_{k}\left(b, G^{a} ; \alpha, \mathbb{B}^{a}\right) \mid \mathbb{B}^{a}\right) \quad \forall \mathbb{B}, \mathbb{B}^{a}
$$

\footnotetext{
${ }^{9}$ The identification approach can also be adapted to several models of endogenous participation as in Haile, Hong, and Shum (2003), and is done so in the application in Section 5.
} 
According to the assumption of exogenous bidder participation, and the equilibrium argument that when evaluated at the true externality parameters, the inverse bid function $\xi_{k}$ is a true description of bidding behavior, the above equality must hold for all observed bidder sets, $\mathbb{B}, \mathbb{B}^{a}$, at the true parameter value, $\alpha^{*}$.

Identification then requires that the equalities like equation (11), formed by observing different bidder sets, only hold at the true parameter value, and would not hold for at least one pair of observed bidder sets, $\mathbb{B}, \mathbb{B}^{a}$, for any alternative parameter values, $\widetilde{\alpha} \neq \alpha^{*}$. This can most easily be shown by looking at some percentile of the distribution of valuations, for example the median. For the distribution of $\xi_{k}$ under $\mathbb{B}$ to be the same as the distribution of $\xi_{k}$ under the alternative $\mathbb{B}^{a}$, they must have the same median values (i.e. $\left.\xi_{k}\left(b_{k, \mathbb{B}}^{m e d}, G ; \widetilde{\alpha}, \mathbb{B}\right)=\xi_{k}\left(b_{k, \mathbb{B}^{a}}^{m e}, G^{a} ; \widetilde{\alpha}, \mathbb{B}^{a}\right)\right)$. Thus identification amounts to showing that there is only one set of parameters for which the median values are equal for all pairs of observed bidder sets $\mathbb{B}$ and $\mathbb{B}^{a}$, since they must be equal at the true parameter value, $\alpha^{*}$.

Expanding out the median equality for two observed bidder sets, $\mathbb{B}$ and $\mathbb{B}^{a}$, I get:

$$
\begin{aligned}
& \left.\left.\xi_{k}\left(b_{k, \mathbb{B}}^{m e d}, G ; \widetilde{\alpha}\right\}, \mathbb{B}\right)=\xi_{k}\left(b_{k, \mathbb{B}^{a}}^{m e d}, G^{a} ; \widetilde{\alpha}\right\}, \mathbb{B}^{a}\right) \\
& \Leftrightarrow \\
& b_{k, \mathbb{B}}^{m e d}-b_{k, \mathbb{B}^{a}}^{m e d}+\left(\frac{H_{k}\left(b_{k, \mathbb{B}}^{m e d} \mid \mathbb{B}\right)}{H_{k}^{\prime}\left(b_{k, \mathbb{B}}^{m e d} \mid \mathbb{B}\right)}-\frac{H_{k}\left(b_{k, \mathbb{B}^{a}}^{m e d} \mid \mathbb{B}^{a}\right)}{H_{k}^{\prime}\left(b_{k, \mathbb{B}^{a}}^{m e d} \mid \mathbb{B}^{a}\right)}\right)+ \\
& \left(\sum_{k^{\prime}}\left[\widetilde{\alpha_{k k^{\prime}}}\left(n_{k^{\prime}}-\mathbf{1}\left\{k^{\prime}=k\right\}\right) \frac{\operatorname{Pr}\left(\max _{l \neq i_{k}, j_{k^{\prime}} \in B^{a}} b_{l} \leq b_{k, \mathbb{B}^{a}}^{m e d} \mid \mathbb{B}^{a}\right) g_{k^{\prime}}\left(b_{k \mathbb{B}^{a}}^{m e d} \mid \mathbb{B}^{a}\right)}{H_{k}^{\prime}\left(b_{k, \mathbb{B}^{a}}^{m e d} \mid \mathbb{B}^{a}\right)}\right]\right. \\
& \left.-\sum_{k^{\prime}}\left[\widetilde{\alpha_{k k^{\prime}}}\left(n_{k^{\prime}}-\mathbf{1}\left\{k^{\prime}=k\right\}\right) \frac{\operatorname{Pr}\left(\max _{l \neq i_{k}, j_{k^{\prime}} \in B} b_{l} \leq b_{k, \mathbb{B}}^{m e d} \mid \mathbb{B}\right) g_{k^{\prime}}\left(b_{k, \mathbb{B}}^{m e d} \mid \mathbb{B}\right)}{H_{k}^{\prime}\left(b_{k, \mathbb{B}}^{m e d} \mid \mathbb{B}\right)}\right]\right)=0
\end{aligned}
$$

Equation (13) is linear in the externality parameters, $\left\{\widetilde{\alpha_{k k^{\prime}}}\right\}$. As more variation in bidder sets is observed, then the number of identifying equalities increases, leading to a system of equations that are linear in the parameters. Letting $S_{k}$ be the number of observed bidder sets that contain a bidder of type $k$, this system can be represented in matrix form as $C \tilde{\alpha}=C^{L C}$, where $C$ is a $\sum_{k=1}^{K}\left(S_{k}-1\right) \times L$ matrix and $C^{L C}$ is a $\sum_{k=1}^{K}\left(S_{k}-1\right) \times 1$ vector.

Then the problem of identification can be reposed as one of finding a unique solution to the above system. The uniqueness of the solution to the above system of equalities depends on the rank of the matrix $C$, which in turn depends on the observed variation in bidder sets. If the $\operatorname{rank}(C) \geq L$, then there is at most one solution to this system of linear equations. Since the true parameter values, $\alpha^{*}$, must be a solution to the system, then if the $\operatorname{rank}(C)$ is large enough, the only way alternative 
parameter values, $\tilde{\alpha}$, will satisfy all of the observed equalities, is if $\tilde{\alpha}=\alpha^{*}$. So the externality parameters are identified, leading to the following proposition.

Proposition 1. Assume bidder participation is exogenous (i.e. $F_{k}(\cdot ; \mathbb{B})=F_{k}\left(\cdot ; \mathbb{B}^{a}\right), \forall \mathbb{B}, \mathbb{B}^{a}$ ) and that inverse bid function $\xi_{k}(b, G ; \alpha, \mathbb{B})$ is strictly increasing in $b$ for $b \in\left[\beta_{k}\left(\underline{v_{k}}\right), \beta_{k}\left(\overline{v_{k}}\right)\right]$. Let $C$ be the matrix described above, constructed by stacking equalities of the form of equation (12), for all bidder types $k$ and all pairs of observed bidder sets, $\mathbb{B}$ and $\mathbb{B}^{a}$. Then if enough variation in bidder sets is observed so that $\operatorname{rank}(C) \geq L$, the externality parameters $\alpha$ are identified.

Proof. Proof is in the Appendix.

Making additional assumptions on bidder distributions can increase the set of equations, and thus ease identification. For example assuming that the median values of bidder distributions for bidders of all types are equal, or further restricting bidder distributions to be symmetric, will increase the $\operatorname{rank}(C)$ and improve identification. Imposing symmetry on the externality parameters between two types of bidders also eases identification.

Once the externality parameters have been identified, identification of the distributions of valuations follows from the existing literature on the identification of distributions of valuations in structural auction models. This is because identification of the externality parameters allows me to identify the pseudo-valuations, which were previously functions of the potential parameter values. Knowledge of the pseudo-values then allows me to identify the distributions of valuations as in Guerrge, Perrigne, and Vuong (2000).

\subsection{Estimation}

Estimation follows along the same lines as identification in the previous section. Observations are assumed to come from $T$ independent auctions labeled $t=1, \ldots, T$. In each auction I observe the bids of each bidder as well as each participating bidder's type. Each auction $t$ will have $n_{k}^{t}$ bidders of type $k$ for $k=1, \ldots, K$, and I will denote this set of bidders for each auction as $\mathbb{B}^{t}$. I let $\mathbb{B}^{\cup}$ be the non-repeating set of bidder sets that are observed and $\mathbb{B}_{k}^{\cup} \subset \mathbb{B}^{\cup}$ be those sets for which $n_{k} \geq 1$. Additionally I will denote the cardinality of these sets as $S=\left|\mathbb{B}^{\cup}\right|$ and $S_{k}=\left|\mathbb{B}_{k}^{\cup}\right|$. Thus $S$ is the number of different bidder sets observed by the econometrician, and $S_{k}$ is the number of those observed bidder sets that contain a bidder of type $k$. A bidder of type $k$ in an auction $t$ with bidder set $\mathbb{B}$, will have valuation denoted by $v_{k, \mathbb{B}}^{i t}$ and bid denoted by $b_{k, \mathbb{B}}^{i t}$. Finally I let $p(i)$ be a function that returns the type of bidder $i$.

The idea behind estimation is very similar to that of identification, where I will use variation in bidder sets to estimate the externality parameters. The strategy is to first use the observed bids 
to compute the distributions and densities in equation (9). Then I will use these estimates and the observed bids to compute either an externality-depenent estimate for the distribution of valuations for each bidder type and bidder set, or to compute an externality-dependent median or mean pseudo-value for each bidder type and bidder set. Then I will use that for a given bidder type, the distribution of pseudo-values, or median or mean pseudo-value, should be the same for each bidder set that bidder type is a part of. This equality across varying bidder sets can then be used to pinpoint an estimate for the externality parameters. In the case of equating the pseudo-value distributions, I will look for the parameter values that minimize the distance between the two estimated distributions. For the estimator that equates the median or mean pseudo-values, the formed system of equalities will be linear in the externality parameters, and so the estimate will just be a solution to this system.

\subsubsection{Distribution Estimates}

The first step in estimation is to get estimates for the distributions and densities in equation (9). The first distribution to estimate is $H_{k}(b \mid \mathbb{B})$, which is the probability that all bidders other than a particular bidder of type $k$, bid below $b$. Letting $T_{\mathbb{B}}$ denote the number of observed auctions with the same set of bidders as that for which I am trying to estimate the distribution for, the estimator for the distribution is given by:

$$
\widehat{H_{k}}(b \mid \mathbb{B})=\frac{1}{T_{\mathbb{B}}} \sum_{t=1}^{T} \frac{1}{n_{k}^{t}} \sum_{i=1}^{n^{t}} \mathbf{1}\left\{\max _{l \neq i \in B^{t}} b^{l t} \leq b\right\} \mathbf{1}\left\{\mathbb{B}^{t}=\mathbb{B}, p(i)=k\right\}
$$

The estimate for the derivative of this distribution is then given by:

$$
\widehat{H_{k}^{\prime}}(b \mid \mathbb{B})=\frac{1}{T_{\mathbb{B}}} \sum_{t=1}^{T} \frac{1}{n_{k}^{t}} \sum_{i=1}^{n^{t}} \frac{1}{h_{H P}} K\left(\frac{b-\max _{l \neq i \in B^{t}} b^{l t}}{h_{H P}}\right) \mathbf{1}\left\{\mathbb{B}^{t}=\mathbb{B}, p(i)=k\right\}
$$

where $K(\cdot)$ is a kernel estimator and $h_{H P}$ is the appropriately chosen bandwidth. Choice of kernel and bandwidth are discussed below in section 4.2. Note that for consistency of these estimates, it is necessary for $T_{\mathbb{B}} \rightarrow \infty$ for all $\mathbb{B}$ for which these estimates are calculated. Then under standard conditions $\widehat{H_{k}}(b \mid \mathbb{B})$ and $\widehat{H_{k}^{\prime}}(b \mid \mathbb{B})$ can be shown to be consistent estimators of $H_{k}(b \mid \mathbb{B})$ and $H_{k}^{\prime}(b \mid \mathbb{B})$, respectively.

For consistent estimators for $\operatorname{Pr}\left(\max _{l \neq i_{k}, j_{k^{\prime}} \in B} b^{l} \leq b \mid \mathbb{B}\right)$ and $g_{k}(b \mid \mathbb{B})$, I propose the following respec- 
tive estimators:

$$
\begin{gathered}
\widehat{\operatorname{Pr}}\left(\max _{l \neq i_{k}, j_{k^{\prime}} \in B} b^{l} \leq b \mid \mathbb{B}\right)=\frac{1}{T_{\mathbb{B}}} \sum_{t=1}^{T} \frac{1}{n_{k}^{t} *\left(n_{k^{\prime}}^{t}-\mathbf{1}\left\{k=k^{\prime}\right\}\right)} \sum_{i=1}^{n_{t}} \sum_{j=1, j \neq i}^{n_{t}} \mathbf{1}\left\{\max _{l \neq i, j \in B^{t}} b^{l t} \leq b\right\} \mathbf{1}\left\{\mathbb{B}^{t}=\mathbb{B}, p(i)=k, p(j)=k^{\prime}\right\} \\
\widehat{g_{k}}(b \mid \mathbb{B})=\frac{1}{T_{\mathbb{B}}} \sum_{t=1}^{T} \frac{1}{n_{k}^{t}} \sum_{i=1}^{n^{t}} \frac{1}{h_{g}} K\left(\frac{b-b^{i t}}{h_{g}}\right) \mathbf{1}\left\{\mathbb{B}^{t}=\mathbb{B}, p(i)=k\right\}
\end{gathered}
$$

where $K(\cdot)$ is a kernel estimator and $h_{g}$ is the appropriately chosen bandwidth. Under standard

conditions $\widehat{\operatorname{Pr}}\left(\max _{l \neq i_{k}, j_{k^{\prime}} \in B} b^{l} \leq b \mid \mathbb{B}\right)$ and $\widehat{g_{k}}(b \mid \mathbb{B})$ are consistent estimates for $\operatorname{Pr}\left(\max _{l \neq i_{k}, j_{k^{\prime}} \in B} b^{l} \leq b \mid \mathbb{B}\right)$ and $g_{k}(b \mid \mathbb{B})$, respectively. I construct consistent estimates of all these distributions and densities for each observed bidder set $\mathbb{B}$, and each type of bidder $k$ observed in that bidder set. With estimates for all of the distribution and density functions in equation (9), I then calculate the pseudo-values for bidders given particular guesses of the externality parameters, and estimate the externality parameter values using one of three different approaches.

\subsubsection{K-S Estimator for $\alpha$}

The first of the three estimators I present, makes inference on the externalities by equating the estimated pseudo-value distributions. This estimator is based on the Kolmogorov-Smirnov test statistic, which tests the equality of two distributions. Here the two distributions that should be equal, are the distributions of pseudo-values for a bidder of a specific type for any two different bidder sets. Since the pseudo-values I construct contain the unknown parameters, then the parameter values that equate the two distributions should be a good estimate of the true parameters.

To construct this estimator, I use the estimates for the distributions from section 3.2.1, and compute the pseudo-values corresponding to each observed bid, using equation (9) for a given guess at the value of the externality parameters, $\alpha^{\prime}$.

$$
\widehat{v_{k, \mathbb{B}}^{i t}}\left(\alpha^{\prime}\right)=b_{k, \mathbb{B}}^{i t}+\frac{\widehat{H_{k}}\left(b_{k, \mathbb{B}}^{i t} \mid \mathbb{B}\right)}{\widehat{H_{k}^{\prime}}\left(b_{k, \mathbb{B}}^{i t} \mid \mathbb{B}\right)}-\sum_{k^{\prime}}\left[\alpha_{k k^{\prime}}^{\prime}\left(n_{k^{\prime}}-\mathbf{1}\left\{k^{\prime}=k\right\}\right) \frac{\widehat{\operatorname{Pr}}\left(\max _{l \neq i_{k}, j_{k^{\prime}} \in B} b^{l} \leq b_{k, \mathbb{B}}^{i t} \mathbb{B}\right) \widehat{g_{k^{\prime}}}\left(b_{k, \mathbb{B}}^{i t} \mid \mathbb{B}\right)}{\widehat{H_{k}^{\prime}}\left(b_{k, \mathbb{B}}^{i t} \mid \mathbb{B}\right)}\right]
$$

Then for each $\mathbb{B}$, and for each type $k$ in $\mathbb{B}$, I estimate the distribution of valuations given guess $\alpha^{\prime}$ :

$$
\widehat{F_{k, \mathbb{B}}}\left(v ; \alpha^{\prime}\right)=\frac{1}{T_{\mathbb{B}}} \sum_{t=1}^{T} \frac{1}{n_{k}^{t}} \sum_{i=1}^{n^{t}} \mathbf{1}\left\{\widehat{v_{k, \mathbb{B}}^{i t}}\left(\alpha^{\prime}\right) \leq v\right\} \mathbf{1}\left\{\mathbb{B}^{t}=\mathbb{B}, p(i)=k\right\}
$$

I then create an objective function that is a sum of the maximum distances between successive es- 
timates of the distributions, and search for the $\alpha^{\prime}$ that minimizes this objective function. Thus if I order the bidder sets in $\mathbb{B}_{k}^{\cup}\left(\left\{\mathbb{B}_{k}^{1}, \ldots, \mathbb{B}_{k}^{S_{k}}\right\}\right)$, then my estimate for the externality parameters is:

$$
\widehat{\alpha}^{K S}=\underset{\alpha^{\prime} \in A}{\operatorname{argmin}}\left\{\sum_{k=1}^{K} \sum_{s=1}^{S_{k}-1} \underset{v \in\left[\underline{\underline{\xi_{k}}\left(\alpha^{\prime}\right)}, \widehat{\left.\bar{\xi}_{k}\left(\alpha^{\prime}\right)\right]}\right.}{\mid F_{k, \mathbb{B}_{k}^{(s+1)}}}\left(v ; \alpha^{\prime}\right)-\widehat{F_{k, \mathbb{B}_{k}^{s}}}\left(v ; \alpha^{\prime}\right) \mid\right\}
$$

Proposition 2. Assume $\mathbb{A}$ is a compact subset of $\mathbb{R}^{L}$. Assume that $\xi_{k}(b, G ; \alpha, \mathbb{B})$ is the equilibrium inverse bid function for a bidder of type $k$, that is strictly increasing in $b$ and continuous in $\alpha$. Also assume that the identification conditions from the previous section hold. Then the estimator $\widehat{\alpha}^{K S}$ defined above is a consistent estimate for the true parameter value $\alpha^{*}$.

Proof. Proof is in the Appendix.

\subsubsection{Median Estimator for $\alpha$}

An alternative estimator for $\alpha$ is to equate the median pseudo-values for bidders of the same type facing auctions with different bidder sets. ${ }^{10}$ The advantage of this estimator is that it is just the solution to a set of linear equations, and thus involves no minimization procedure. The disadvantage of this estimator is that it is very dependent on the median bid, and thus is more susceptible to small sample biases.

For each bidder type $k$ and each bidder set $\mathbb{B}$ that $k$ is in, I calculate the pseudo-value for the median bidder of type $k$ in an auction with bidder set $\mathbb{B}$. I do this by first finding the empirical median bid of a type $k$ bidder in an auction with bidder set $\mathbb{B}$, and denote it $\hat{b}_{k, \mathbb{B}}^{\text {med }}$. Then for each median bid, I use equation (9) to calculate the corresponding pseudo-value for that bid, as a function of the externality parameters.

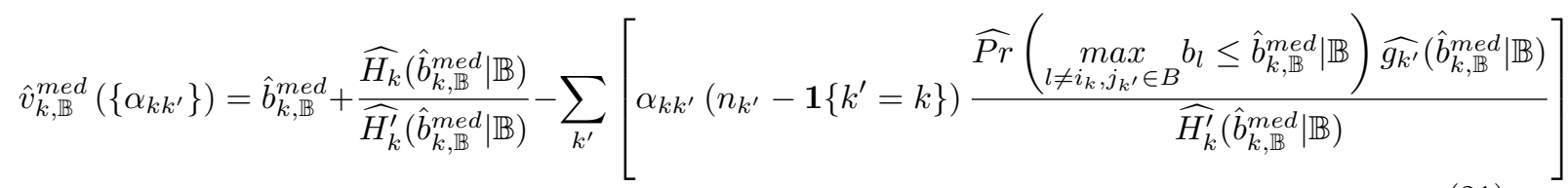

This is a result of the monotonicity of $\xi$.

Then for each bidder type I set the pseudo-values for median bidders from auctions with different bidder sets, equal to each other.

$$
\hat{v}_{k, \mathbb{B}}^{m e d}\left(\left\{\alpha_{k k^{\prime}}\right\}\right)=\hat{v}_{k, \mathbb{B}^{a}}^{m e d}\left(\left\{\alpha_{k k^{\prime}}\right\}\right)
$$

For each bidder type $k$, this gives me $S_{k}-1$ equations, where again $S_{k}$ is the number of observed

\footnotetext{
${ }^{10}$ This could be done for any percentile, not just the median.
} 
bidder sets that include bidder type $k$. All of these equalities are linear functions of the externality parameters and so they form a system of linear equations in the desired parameters.

For each bidder type $k$, I define the matrix $\widehat{C_{k}}$ of size $\left(S_{k}-1\right) \times L$ and the vector $\widehat{C_{k}^{L C}}$ of size $\left(S_{k}-1\right) \times 1$, which will define the system of equalities between the median pseudo-values of bidders of type $k$ in different bidder sets $\mathbb{B}$. Combining the equations for bidders of different types, I construct the matrix $\widehat{C}$ as:

$$
\widehat{C}=\left(\begin{array}{cccc}
\widehat{C_{1}} & 0 & \ldots & 0 \\
0 & \widehat{C_{2}} & \ldots & 0 \\
\vdots & \vdots & \ddots & \vdots \\
0 & 0 & \ldots & \widehat{C_{K}}
\end{array}\right)
$$

and the vector $\widehat{C^{L C}}$ as:

$$
\widehat{C^{L C}}=\left(\begin{array}{c}
\widehat{C_{1}^{L C}} \\
\widehat{C_{2}^{L C}} \\
\vdots \\
\widehat{C_{K}^{L C}}
\end{array}\right)
$$

Then the system of equations I wish to solve for $\alpha$ is given by:

$$
\widehat{C} \alpha=\widehat{C L^{L C}}
$$

When there is enough variation in the bidder sets for identification, then a consistent estimate for the externality parameter is $\widehat{\alpha}^{\text {med }}=\left(\widehat{C}^{\prime} \widehat{C}\right)^{-1} \widehat{C}^{\prime} \widehat{C^{L C}}$. The requirements for consistency of this estimator include the assumptions made for identification, such as monotonicity of the equilibrium bid function, exogenous bidder participation, and that equation (9) holds in equilibrium. Then consistency of the estimator $\widehat{\alpha}^{\text {med }}$, follows straightforwardly from the consistency of the estimated distributions and densities used to construct the pseudo-values in equation (21), and the consistency of the sample median bid:

$$
\widehat{\alpha}^{m e d}=\left(\widehat{C}^{\prime} \widehat{C}\right)^{-1} \widehat{C}^{\prime} \widehat{C^{L C}} \stackrel{p}{\rightarrow}\left(C^{\prime} C\right)^{-1} C^{\prime} C^{L C}=\alpha
$$

Proposition 3. Assume the conditions for identification hold, and the estimated distributions, densities, and median bid, are consistent estimates of their true counterparts. Then the estimator $\widehat{\alpha}^{\text {med }}$, as defined above, is a consistent estimate for the true parameter value $\alpha^{*}$.

\subsubsection{Mean Estimate for $\alpha$}

In addition to equating the median pseudo values (or any other percentile) I can also estimate $\alpha$ by finding the parameter values that equate the mean pseudo-valuations. This estimator is very similar 
to the above median estimator, but instead of getting an estimate for the median pseudo-valuation as a function of the externality parameters, I aim to get an estimate of the mean pseudo-valuation as a function of the externality parameters.

To construct such an estimate, instead of evaluating the estimated distributions at the empirical median bid, I take the mean of each component over the observed sample bids. This amounts to estimating:

$$
\begin{aligned}
& \hat{b}_{k, \mathbb{B}}^{\mu}=\frac{1}{T_{\mathbb{B}}} \sum_{t=1}^{T} \frac{1}{n_{k}^{t}} \sum_{i=1}^{n^{t}} b^{i t} \mathbf{1}\left\{\mathbb{B}^{t}=\mathbb{B}, p(i)=k\right\} \\
& \widehat{E}\left[\frac{H_{k}(b \mid \mathbb{B})}{H_{k}^{\prime}(b \mid \mathbb{B})}\right]=\frac{1}{T_{\mathbb{B}}} \sum_{t=1}^{T} \frac{1}{n_{k}^{t}} \sum_{i=1}^{n^{t}} \frac{\widehat{H_{k}}\left(b^{i t} \mid \mathbb{B}\right)}{\widehat{H_{k}^{\prime}}\left(b^{i t} \mid \mathbb{B}\right)} \mathbf{1}\left\{\mathbb{B}^{t}=\mathbb{B}, p(i)=k\right\} \\
& \widehat{E}\left[\frac{\operatorname{Pr}\left(\max _{l \neq i_{k}, j_{k^{\prime}} \in B} b^{l} \leq b \mid \mathbb{B}\right) g_{k^{\prime}}(b \mid \mathbb{B})}{H_{k}^{\prime}(b \mid \mathbb{B})}\right]=\frac{1}{T_{\mathbb{B}}} \sum_{t=1}^{T} \frac{1}{n_{k}^{t}} \sum_{i=1}^{n^{t}} \frac{\widehat{\operatorname{Pr}}\left(\max _{l \neq i_{k}, j_{k^{\prime}} \in B} b^{l} \leq b^{i t} \mid \mathbb{B}\right) \widehat{g_{k^{\prime}}}\left(b^{i t} \mid \mathbb{B}\right)}{\widehat{H_{k}^{\prime}}\left(b^{i t} \mid \mathbb{B}\right)} \mathbf{1}\left\{\mathbb{B}^{t}=\mathbb{B}, p(i)=k\right\}
\end{aligned}
$$

This estimator then uses the restriction that mean valuations for certain bidder types should be the same across auctions with different bidder sets (i.e. $v_{k, \mathbb{B}}^{\mu}=v_{k, \mathbb{B}^{a}}^{\mu}, \forall \mathbb{B}, \mathbb{B}^{a}$ ). This assumption is used to construct similar matrices as before, $\widehat{C^{\mu}}$ and $\widehat{C^{L C, \mu}}$, which have the same form as the previous matrices but with the mean estimates in equations (27)-(29) replacing the median estimates. Once again consistency can be shown for the estimator $\widehat{\alpha}^{\mu}=\left({\widehat{C^{\mu}}}^{\prime}{\widehat{C^{\mu}}}^{-1}{\widehat{C^{\mu}}}^{\prime} \widehat{C^{L C, \mu}}\right.$.

\subsubsection{Estimate for Distribution of Valuations}

Once I have estimates of the externality parameters, I follow the existing literature to construct estimates of the distributions of valuations. Given any estimator of the parameters, $\widehat{\alpha}, \mathrm{I}$ can compute according to equation (18), the corresponding pseudo-values $\widehat{v^{i t}}(\widehat{\alpha})$ for each observed bid $b^{i t}$. Then a bidder-type specific distribution of valuations that doesn't depend on bidder sets is constructed similarly to equation (19):

$$
\widehat{F_{k}}(v)=\frac{1}{T_{k}} \sum_{t=1}^{T} \frac{1}{n_{k}^{t}} \sum_{i=1}^{n^{t}} \mathbf{1}\left\{\widehat{v^{i t}}(\widehat{\alpha}) \leq v\right\} \mathbf{1}\{p(i)=k\}
$$

where $T_{k}$ is the number of observed auctions that contain bidders of type $k$. Thus in addition to having an estimate of the externality parameters, I also have an estimate for the distributions of valuations. 


\section{Monte Carlo Experiments}

\subsection{Setup}

To assess the performance of the different externality parameter estimators I ran several Monte Carlo experiments. In the experiments bidders are one of $K=2$ types denoted by $M$ and $L$. One can think of type $M$ bidders as mill bidders in the timber auction application, and type $L$ bidders as loggers.

I ran the experiments under 3 different assumptions about the distributions of bidder valuations. The first assumption was that bidder distributions were asymmetric. In this case I chose the distribution of valuations for mills, $F_{M}(\cdot)$, to be uniform on $[0,1]$, and the distribution of valuations for loggers, $F_{L}(\cdot)$, to be uniform on $[0,2]$. I chose uniform distributions so that it was possible to calculate the corresponding bids for a variety of possible bidder sets. For the externality parameters, I chose values of $\alpha_{M M}=0.3, \alpha_{L L}=0.2$, and $\alpha_{M L}=\alpha_{L M}=0.1$.

The second assumption I simulated auctions under, was that bidder distributions were asymmetric, but had the same median and mean. Here I chose the distribution of valuations for mills, $F_{M}(\cdot)$, to be uniform on $[0.25,1.25]$, and the distribution of valuations for loggers, $F_{L}(\cdot)$, to be uniform on $[0,1.5]$. Again for the externality parameters, I chose values of $\alpha_{M M}=0.3, \alpha_{L L}=0.2$, and $\alpha_{M L}=\alpha_{L M}=0.1$.

The third and final assumption I made on bidder distributions, was symmetry between the two distributions. Here I chose both distributions to be uniform on $[0,1]$, and for all the parameters to have the same values as before.

Under each assumption, I created auctions with 4 different bidder sets. These were auctions with two mills, auctions with three mills, auctions with two loggers, and auctions with one mill and one logger. The bidder sets that I could simulate auctions for was restricted by the difficulty in calculating bid functions for bidders in these auctions. Even with uniform valuations and the smallest possible number of participants, I could not get an analytic solution to equilibrium equation (3) for auctions with bidders of different types. Thus to get bid functions in the case of auctions with one mill and one logger, I had to solve equation (3) numerically, which could have added error to this procedure.

For each Monte Carlo run I simulated a sample of 100 auctions, 25 for each of the 4 different bidder sets. With each sample, I then calculated the K-S, median, and mean estimates for the parameters. I ran the experiments 100 different times for each of the three assumptions on bidder value distributions.

\subsection{Implementation}

Practical considerations included the choices of both the kernel and the bandwidths, and how to trim in order to mitigate the bias at the boundaries caused by the kernel estimator. For choice of kernel I followed both Li, Perrigne, and Vuong (2002) and Campo, Perrigne, and Vuong (2003), and used 
a triweight kernel. This kernel satisfies the assumptions of Guerre, Perrigne, and Vuong (2000), and it has the form $K(u)=(35 / 32)\left(1-u^{2}\right)^{3} \mathbf{1}(|u| \leq 1)$. As noted in Li, Perrigne, and Vuong (2002), the choice of kernel does not have much of an impact in practice, and I chose this form for the kernel to follow the existing literature.

In choosing the appropriate bandwidths I again followed both Guerre, Perrigne, and Vuong (2000) and Li, Perrigne, and Vuong (2002). The bandwidths take the form of $h_{H P}=h_{g}=c * T^{-1 / 5}$. The constant is $c=2.978 \times 1.06 \hat{\sigma}_{b_{k}}$ where $\hat{\sigma}_{b_{k}}$ is the standard deviation of all bids from bidders of type $k$, in auctions with the particular bidder set I am calculating the density for.

It is well known that kernel density estimators suffer from biases near the boundaries of their support. This will affect my K-S and mean estimates for the externality parameters (but not my median estimator since it does not depend on bids near the boundaries). To reduce the effect of this bias on the estimated pseudo-values, Guerre, Perrigne, and Vuong (2000) suggest a trimming procedure that is followed by most of the literature. While I also trimmed in order to mitigate the boundary effects, I chose a different procedure than that of Guerre, Perrigne, and Vuong (2000). Instead of trimming based on the bandwidths, I chose to trim all bid observations that were below the 10th percentile or above the 90th percentile of all bids from bidders of that given type in auctions with a given bidder set.

The reason I chose to trim based on the 10th and 90th percentile of bids rather than follow Guerre, Perrigne, and Vuong (2000) and trim based on the bandwidths, was that trimming based on the bandwidths makes it difficult to compare two distributions of pseudo-values. Trimming mill bids for a particular bidder set within one bandwidth of the mill bid support for that bidder set gives an interval of mill pseudo-valuations that is comparatively different than the interval of mill pseudo-valuations in auctions with another bidder set that results from trimming those bids within one bandwidth of the mill bid support in that different bidder set. Since my K-S estimation strategy relies heavily on comparing the two distributions of pseudo-valuations, a trimming procedure which trims the pseudo-values for a particular bidder type facing different bidder sets in a more equitable fashion is desirable. I believe trimming based on the 10th and 90th percentile of bids results in comparable ranges of pseudo-values for bidders facing different bidder sets.

\subsection{Results}

Before presenting the results it is instructive to graphically look at how identification and estimation of the model parameters are achieved. Figure 1 shows the true and estimated bid functions for mill bidders in the first auction set with only two mill bidders. As expected, pseudo-valuations are pretty close to the true valuations when evaluated at the true externality, except near the boundaries where 
the estimated valuations are a lot larger then they should be. Yet pseudo-values constructed using incorrect values for the externality parameter, are not good approximations to the true valuations for any interval of bids. This implies that the distribution of pseudo-values using the correct externality parameter should match up well across different auctions, while the distribution of pseudo-values using incorrect externality parameters should not, supporting the estimators of this paper.

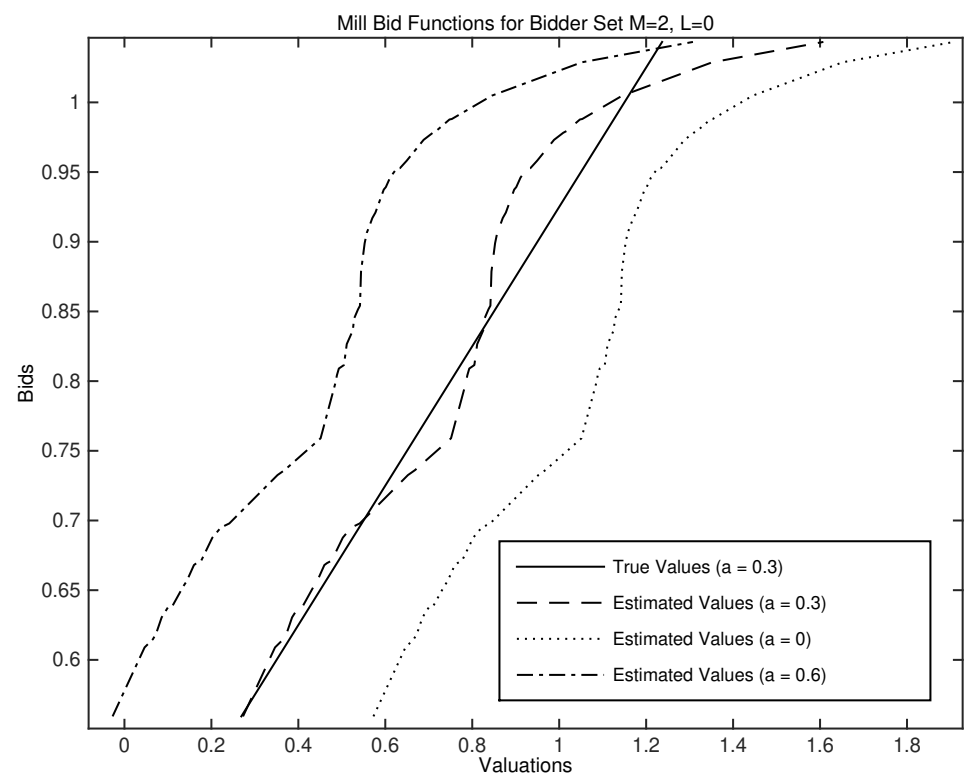

Figure 1: True mill bid function when facing 1 other mill bidder, compared to estimated mill bid function when facing 1 other mill bidder, evaluated at 3 different choices of $\alpha$

For the estimators to work it is also important that the distributions of pseudo-values for bidders of the same type across different auctions, match up well when evaluated at the true parameter value, but do not match up well when evaluated at different values for the externality parameter. Figure 2 shows the distributions of mill pseudo-values across auctions with different bidder sets when all pseudo-values are evaluated at the true parameter values. As can be seen from the figure, the distributions match up reasonably well, supporting the notion that at the true value for the externality parameters, the distributions of valuations from different bidder sets should be close to each other. 


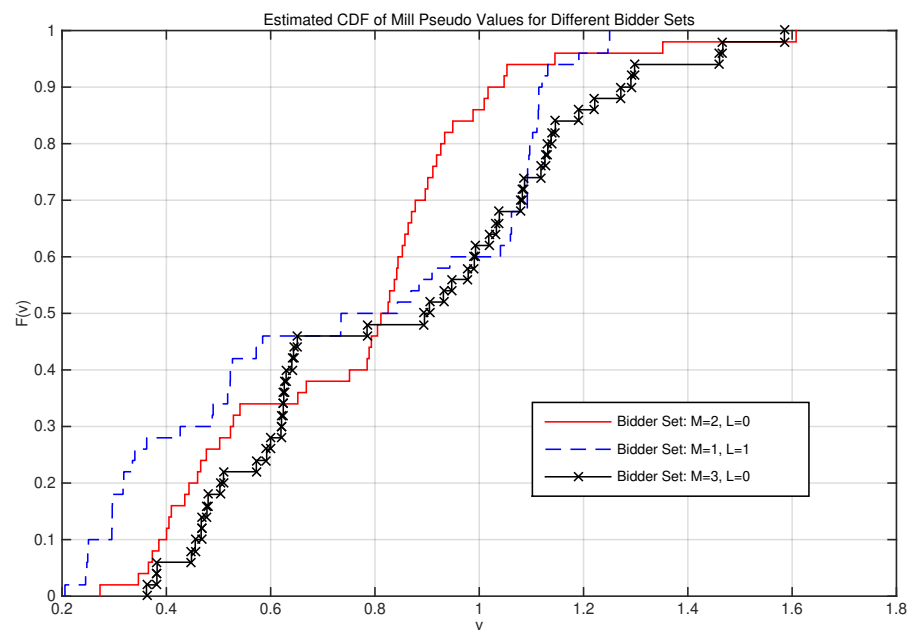

Figure 2: Distributions of mill pseudo-values in auctions with different bidder sets

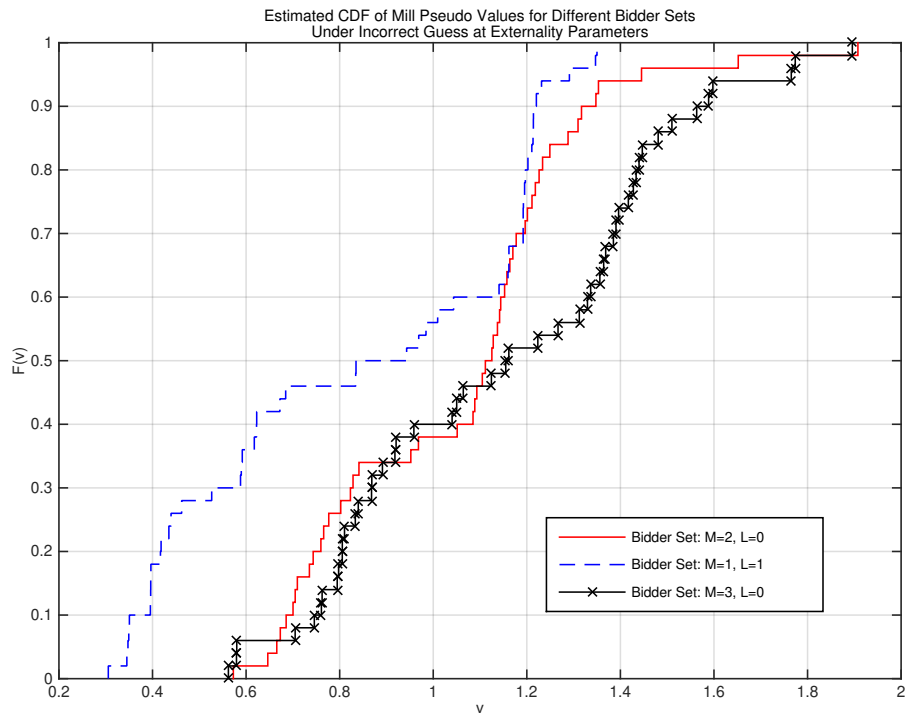

Figure 3: Distribution of mill pseudo-values in auctions with different bidder sets when pseudo-values are constructed assuming that the externality parameter is the 0 -vector

Figure 3 presents the estimated distributions of pseudo-values assuming, incorrectly, that there is no externality parameters (i.e. $\alpha$ is the 0 -vector). Comparing Figures 2 and 3, one can see that the distributions match up better in Figure 2 when pseudo-values are constructed using the true parameter value. This illustrates how the externality parameters are identified in this paper, by 
finding the parameter values that most closely match up the subsequent pseudo-value distributions for bidders of the same type across auctions with different bidder sets.

The results for each of the Monte Carlo experiments are given in Tables 1-3. Each table corresponds to a different assumption on the distributions of valuations. Table 1 shows the results for all three estimators, assuming asymmetric bidder distributions. Table 2 assumes that distributions are asymmetric but have the same median and mean, and Table 3 assumes symmetric distributions. For each of the three parameter values I report the mean and median parameter estimates along with the 10 th and 90th percentiles.

Table 1: Monte Carlo Results when $F_{M}(\cdot) \sim U(0,1)$ and $F_{L}(\cdot) \sim U(0,2)$

\begin{tabular}{|c|c|c|c|c|}
\hline$\alpha_{M M}=0.3$ & Mean & $50 \%$ & $10 \%$ & $90 \%$ \\
\hline$\widehat{\alpha}^{K S}$ & 0.310402 & 0.315684 & 0.231812 & 0.392263 \\
$\widehat{\alpha}^{\text {med }}$ & 0.323138 & 0.304055 & 0.245993 & 0.465312 \\
$\widehat{\alpha}^{\mu}$ & 0.396946 & 0.341067 & 0.280055 & 0.567736 \\
\hline$\alpha_{L L}=0.2$ & Mean & $50 \%$ & $10 \%$ & $90 \%$ \\
\hline$\widehat{\alpha}^{K S}$ & 0.207934 & 0.207037 & 0.161094 & 0.24293 \\
$\widehat{\alpha}^{\text {med }}$ & 0.200447 & 0.200639 & 0.060975 & 0.281679 \\
$\widehat{\alpha}^{\mu}$ & 0.069564 & 0.140684 & -0.12821 & 0.254566 \\
\hline$\alpha_{M L}=0.1$ & Mean & $50 \%$ & $10 \%$ & $90 \%$ \\
\hline$\widehat{\alpha}^{K S}$ & 0.089134 & 0.091762 & 0.073335 & 0.104138 \\
$\widehat{\alpha}^{\text {med }}$ & 0.086416 & 0.07517 & 0.044095 & 0.108153 \\
$\widehat{\alpha}^{\mu}$ & 0.133491 & 0.101957 & 0.068387 & 0.196818 \\
\hline
\end{tabular}

Table 2: Monte Carlo Results when $F_{M}(\cdot) \sim U(.25,1.25)$ and $F_{L}(\cdot) \sim U(0,1.5)$

\begin{tabular}{|c|c|c|c|c|}
\hline$\alpha_{M M}=0.3$ & Mean & $50 \%$ & $10 \%$ & $90 \%$ \\
\hline$\widehat{\alpha}^{K S}$ & 0.275692 & 0.290208 & 0.215411 & 0.316278 \\
$\widehat{\alpha}^{\text {med }}$ & 0.308971 & 0.320055 & 0.275379 & 0.332045 \\
$\widehat{\alpha}^{\mu}$ & 0.288794 & 0.29161 & 0.280649 & 0.301967 \\
\hline$\alpha_{L L}=0.2$ & Mean & $50 \%$ & $10 \%$ & $90 \%$ \\
\hline$\widehat{\alpha}^{K S}$ & 0.216209 & 0.204757 & 0.199 & 0.256109 \\
$\widehat{\alpha}^{\text {med }}$ & 0.193526 & 0.184952 & 0.14061 & 0.249794 \\
$\widehat{\alpha}^{\mu}$ & 0.208355 & 0.209329 & 0.186527 & 0.227011 \\
\hline$\alpha_{M L}=0.1$ & Mean & $50 \%$ & $10 \%$ & $90 \%$ \\
\hline$\widehat{\alpha}^{K S}$ & 0.101512 & 0.103079 & 0.091136 & 0.109159 \\
$\widehat{\alpha}^{\text {med }}$ & 0.097503 & 0.106825 & 0.052478 & 0.135752 \\
$\widehat{\alpha}^{\mu}$ & 0.102851 & 0.102708 & 0.085792 & 0.116836 \\
\hline \multicolumn{4}{|r|}{}
\end{tabular}


Table 3: Monte Carlo Results when $F_{M}(\cdot) \sim U(0,1)$ and $F_{L}(\cdot) \sim U(0,1)$

\begin{tabular}{|c|c|c|c|c|}
\hline$\alpha_{M M}=0.3$ & Mean & $50 \%$ & $10 \%$ & $90 \%$ \\
\hline$\widehat{\alpha}^{K S}$ & 0.323712 & 0.327882 & 0.27884 & 0.3598 \\
$\widehat{\alpha}^{\text {med }}$ & 0.31968 & 0.315192 & 0.290128 & 0.364061 \\
$\widehat{\alpha}^{\mu}$ & 0.296792 & 0.29757 & 0.288866 & 0.308224 \\
\hline$\alpha_{L L}=0.2$ & Mean & $50 \%$ & $10 \%$ & $90 \%$ \\
\hline$\widehat{\alpha}^{K S}$ & 0.204596 & 0.198164 & 0.184214 & 0.234025 \\
$\widehat{\alpha}^{\text {med }}$ & 0.185348 & 0.189237 & 0.13773 & 0.224511 \\
$\widehat{\alpha}^{\mu}$ & 0.203725 & 0.203062 & 0.196838 & 0.210059 \\
\hline$\alpha_{M L}=0.1$ & Mean & $50 \%$ & $10 \%$ & $90 \%$ \\
\hline$\widehat{\alpha}^{K S}$ & 0.094012 & 0.101607 & 0.089822 & 0.104018 \\
$\widehat{\alpha}^{\text {med }}$ & 0.094973 & 0.099049 & 0.063918 & 0.127218 \\
$\widehat{\alpha}^{\mu}$ & 0.099484 & 0.103214 & 0.082929 & 0.107724 \\
\hline
\end{tabular}

The results indicate that all three approaches perform well in estimating the externality parameters. In all cases the 10th percentile and 90th percentile estimates bound the true value of the parameter. In most cases the mean and median estimates are also very close to the true $\alpha$ value. As would be expected, the estimates perform better as more restrictions are put on the distribution functions. This seems to affect the mean estimator the most. For the case of no restrictions (completely asymmetric value distributions), the mean estimator seems to have a difficult time pinpointing the parameter values, and there is a lot of variance in the resulting estimates. In this case there are only four restrictions on the parameters, and three parameters to estimate, and so it is not surprising that the estimator does not perform too well. As more restrictions are put on the distributions, the mean estimator's performance improves, and it is able to get pretty accurate estimates for the case of symmetric value distributions.

\section{Application to USFS Timber Auctions}

I now apply the above strategy to look for the existence of auction externalities in timber auctions held by the U.S. Forest Service. This is an interesting setting to look at externalities as there have recently been a series of antitrust cases brought against a lumber mill, accusing the mill of predatory bidding. I thus use the above strategy to look at how bidding behavior in timber auctions is affected by the identities of the other auction participants, to infer whether downstream competition in the lumber industry affects upstream timber markets, and to what extent this outside competition affects auction outcomes. 


\subsection{Industry Background}

In 2007 the U.S. Supreme Court heard the case of Weyerhaeuser Company vs. Ross-Simmons Hardwood Lumber Company, Inc, in which Weyerhaeuser Company was accused of placing higher bids in timber auctions in order to achieve monopsony power in the market for timber. According to Rausser and Foote (2012), testimony indicated that, "Weyerhaeuser sometimes bought more sawlogs than it needed with the purpose of keeping them from competitors." This is consistent with the idea of auction externalities, where certain firms bid more in an auction in order to keep the auctioned item away from specific competitors.

One of the points of contention in this case was to what degree Weyerhaeuser Company's higher bid prices for timber were affected by the competition they faced with other lumber companies, and their desire to lessen that competition by keeping timber away from these competitors. The identification and estimation strategy of this paper can be used to look at Weyerhaeuser's incentives for predatory bidding by looking at whether certain lumber firms bid higher in auctions in which their fellow bidders are lumber companies they compete strongly with in the downstream lumber market. Deriving the size of this external valuation is important in determining whether or not downstream incentives are a significant driving force behind lumber firms' bids in timber markets.

Here I look at timber auctions in general to see whether outside competition between bidding mills has a significant impact on bids. The time period I look at (1982 to 1990) is before the alleged predation, and my study encompasses a broader set of regions (the Weyerhaeuser case involved auctions in only Oregon and Washington) and species of timber (Weyerhaeuser was accused of predatory bidding in alder sawlogs) than the case examined above. Still, the general implications for how downstream competition affects bidding, are important when considering whether or not bidding to keep timber away from rivals does indeed happen in the timber market. To my knowledge, no prior work has looked at the effect downstream competition has had on timber auction outcomes.

These auctions are conducted by the U.S Forest Service in order to allocate the right to remove all timber from a given tract. The Forest Service initially identifies a tract to be sold off and conducts a "cruise" of the tract to get appraisal estimates of the total value of the tract, including items such as logging and manufacturing costs. This is used to determine the reserve price set in the auction, which is generally viewed as non-binding. ${ }^{11}$ The characteristics of the tract and the estimated appraisal values are made public to the bidding firms prior to the auction.

The Forest Service uses a mix of open and sealed bid auction formats, but I focus here on auctions that use the sealed bid format. ${ }^{12}$ Bids are made on a per-unit (thousand board-feet of timber) basis. Most of the literature has considered a model of private values for these "scaled sale" auctions since

\footnotetext{
${ }^{11}$ Haile (2001) provides a discussion for why reserve prices in timber auctions are generally non-binding.

${ }^{12}$ Athey, Levin, and Seira (2011) provide a comparison between the open and sealed bid format in timber auctions.
} 
bidders are highly specialized firms whom differ in terms of their own inventory sizes of both uncut timber and the end-product lumber, and differ in terms of production costs. ${ }^{13}$ Once the auction is completed, the winning bidder has a set period of time (set in the contract) to then harvest the timber on the tract.

The bidders in these auctions range from large vertically integrated conglomerates to small logging companies with less than 25 employees. Based on Athey, Levin, and Seira (2011), I classify bidders into three groups: mills that have manufacturing capacity, loggers that do not have manufacturing capacity, and small businesses with less than 25 employees. This is meant to group firms of the same type in the downstream lumber market. Another potentially important way to classify bidders based on their downstream market, is by their geographic location. This is not explored in this paper, because while mill assembly costs and transportation costs determine a local geographic zone for timber supply for each mill, the downstream market for lumber is generally considered to be global in nature, such that externalities based on geographic location appear to be less important.

\subsection{Data}

I look at sealed-bid auctions in all 9 regions of the U.S. Forest Service that took place between 1982 and 1990. I restrict the sample set to after 1981 since policy changes in 1981 reduced the significance of resale affecting bidder valuations, an important issue discussed in Haile (2001). I restrict my sample of auctions to those where more than one bid was actually received and the item was sold. In a small portion of auctions, entry is restricted to small businesses, and so I don't include those auctions in my sample.

The data I use comes from the U.S. Forest Service ${ }^{14}$, and for each auction contains information on the date and location of the auction, the type of auction format used, the length of the contract, the bids and bidder identities, and the cruise estimates. The bid data contains the per-unit bid price placed by each firm for each species tract. Using the data on the volume of each species, I combine the separate bids for each species to get a total bid for each bidder, which in practice is what is used to determine the auction winner. The cruise estimates provide information on the volume and density of the tract, as well as estimates of the selling value, the manufacturing costs, road construction costs, the logging costs, and the advertised rate (which is set as the reserve price). I also compute the Herfindahl index for the concentration of species across a tract, since specialized mills may place a higher value on tracts where the timber is concentrated in only a few species. Since there is considerable heterogeneity

\footnotetext{
${ }^{13}$ Haile, Hong, and Shum (2003) found in the case of scale sales that only one out of ten of their tests rejected the null hypothesis of private values at the $10 \%$ level. Prior literature that has assumed private values for timber auctions includes Baldwin, Marshall, and Richard (1997), Cummins (1994), Elyakine, Laffont, Loisel, and Vuong (1994), Haile (2001), Haile and Tamer (2003), Lu and Perrigne (2008), and Paarsch (1997).

${ }^{14}$ Thank you to Phil Haile who provided the data on his website.
} 
in the tracts being auctioned off, these observable characteristics are used to control for observable heterogeneity in the estimation below. ${ }^{15}$

Table 4 provides summary statistics of the tract characteristics and the auction outcomes. Mills win $57 \%$ of the auctions, loggers win $42 \%$, and small businesses win less than $1 \%$ of the auctions. On average auctions also have more mill participants than logger participants, with the average auction containing 2.05 mill entrants and 1.67 logger entrants. I am particularly interested in how mill bidding behavior is affected by the entry of mills (whom they compete against in the downstream lumber market) differently from the entry of another logger competitor or small business.

Table 4: Timber Auction Data Summary Statistics

\begin{tabular}{|c|c|c|c|}
\hline Variable & Mean & Median & Std. dev. \\
\hline Winning Bid (\$) & 101,942 & 32,827 & 194,408 \\
\hline Per Unit Winning Bid $(\$ / \mathrm{mbf})$ & 96.54 & 82.00 & 74.71 \\
\hline Num of Bidders & 3.76 & 3.00 & 1.85 \\
\hline Num of Mills & 2.05 & 2.00 & 1.87 \\
\hline Num of Loggers & 1.67 & 1.00 & 1.87 \\
\hline Num of Small Businesses & 0.04 & 0.00 & 0.41 \\
\hline Mill wins auction & 0.57 & & \\
\hline Logger wins auction & 0.42 & & \\
\hline Timber Volume (mbf) & 1,032 & 390 & 10,786 \\
\hline Density (mbf/acre) & 4.65 & 1.97 & 9.20 \\
\hline Acres & 3,593 & 227 & 113,153 \\
\hline Advertised Rate $(\$)$ & 61,233 & 15,636 & 130,406 \\
\hline Selling Value $(\$)$ & 578,924 & 167,110 & $1,313,678$ \\
\hline Manufacturing Costs $(\$)$ & $2,575,675$ & 108,663 & 870,118 \\
\hline Logging Costs $(\$)$ & $1,265,596$ & 76,373 & 484,346 \\
\hline Road Construction Costs $(\$)$ & 6,600 & 394 & 123,308 \\
\hline Per Unit Advertised Rate $(\$ / \mathrm{mbf})$ & 64.39 & 51.43 & 52.47 \\
\hline Per Unit Selling Value $(\$ / \mathrm{mbf})$ & 344.60 & 361.23 & 125.72 \\
\hline Per Unit Manufactruing Costs $(\$ / \mathrm{mbf})$ & 178.38 & 178.18 & 45.63 \\
\hline Per Unit Logging Costs $(\$ / \mathrm{mbf})$ & 130.83 & 127.05 & 45.97 \\
\hline Per Unit Road Construction Costs $(\$ / \mathrm{mbf})$ & 15.30 & 2.59 & 231.88 \\
\hline Contract Length (Years) & 1.96 & 1.81 & 1.48 \\
\hline Salvage Sale & 0.13 & 0.00 & 0.34 \\
\hline Species HHI & 0.60 & 0.55 & 0.22 \\
\hline
\end{tabular}

\subsection{Preliminary Evidence}

I am interested in whether bidders in timber auctions increase (or decrease) their bids based on the types of competitors they are facing in the auction. Bidders compete with each other in a downstream

\footnotetext{
${ }^{15}$ I also consider unobserved heterogeneity using the approach of Haile, Hong, and Shum (2003), which is discussed more in section 5.4 below.
} 
market, and so there may be an incentive for firms to bid higher than their value in auctions where they face strong downstream competitors, so that that they can keep those competitors from getting the timber. To initially see if this is the case I ran a regression of the logarithm of the total value of each bid on the number of bidding competitors and the number of mill competitors if the bidder was a mill, and the number of logger competitors if the bidder was a logger. I also controlled for the auction characteristics described above, and used dummies for the year and for the region of the auction. The results of the regression are in Table 5 .

The preferred specifications are in column (4) and column (5), which includes dummies for both the year of the auction and the region of the timber tract. Column (4) includes all of the variables used in the Forest Service's appraisal as independent variables, while column (5) includes only the advertised rate, which incorporates all of these revenue and cost appraisal estimates. Throughout all of the specifications, the coefficient on the effect of the number of competing mills on a mill bidder's bid is positive and significant. The coefficient in column (4) of 0.0211 , is interpreted as saying that for each additional mill bidder entrant, other mill bidders will increase their bid by roughly $2 \%$. This is holding the number of bidders in the auction constant. This indicates that mill bidders are increasing their bids by more when facing additional competition from other mills than if that additional competition is from other loggers or small businesses. This is evidence of auction externalities where mill bidders are bidding above their valuations for timber tracts in which they are competing with mills that they also compete with in the downstream lumber market.

\subsection{Estimation Procedure}

Given the preliminary evidence of externalities in timber auctions, I apply the structural estimation technique of this paper to the case of U.S. Forest Service timber auctions. I am particularly interested in the externalities between mills since many of these mills later compete against each other in the downstream lumber market. I assume that bidders of the same type have the same distribution of valuations for a given tract of timber, but allow for asymmetries between the different types of bidders.

There is considerable observable heterogeneity between the timber tracts being auctioned, and so I homogenize the bids using the auction characteristics available in the data. Most of this observed heterogeneity can be captured by the advertised rate set by the Forest Service. Still, like Aradillas-Lopez, Gandhi, and Quint (2013), I use the other observable characteristics in addition to the advertised rate when controlling for the observed differences between auctions. Thus to homogenize the bids I regress the $\log ($ bid $)$ with the cruise estimates, species HHI, the contract length, dummy indicators for year and region of the auction, and then dummies for the number of auction participants of each type. I then combine the residuals with the corresponding number of auction participants of each type intercept 
Table 5: Preliminary Regression on $\ln ($ bid $)$

\begin{tabular}{|c|c|c|c|c|c|}
\hline \multicolumn{6}{|c|}{ Dep. Variable: $\ln ($ bid $)$} \\
\hline & Spec (1) & Spec (2) & Spec (3) & Spec (4) & Spec (5) \\
\hline Mill Dummy & $\begin{array}{c}-0.0117 \\
(0.0113)\end{array}$ & $\begin{array}{c}-0.0002 \\
(0.0113)\end{array}$ & $\begin{array}{c}-0.0095 \\
(0.0112)\end{array}$ & $\begin{array}{c}0.0034 \\
(0.0112)\end{array}$ & $\begin{array}{c}0.0024 \\
(0.0112)\end{array}$ \\
\hline Num of Bidders & $\begin{array}{c}0.0549 * \\
(0.0020)\end{array}$ & $\begin{array}{l}0.0513 * \\
(0.0020)\end{array}$ & $\begin{array}{l}0.0537 * \\
(0.0020)\end{array}$ & $\begin{array}{l}0.0500 * \\
(0.0020)\end{array}$ & $\begin{array}{l}0.0505 * \\
(0.0020)\end{array}$ \\
\hline Num of Mill if Mill & $\begin{array}{l}0.0199 * \\
(0.0025)\end{array}$ & $\begin{array}{c}0.0227 * \\
(0.0025)\end{array}$ & $\begin{array}{c}0.0186 * \\
(0.0024)\end{array}$ & $\begin{array}{l}0.0211 * \\
(0.0024)\end{array}$ & $\begin{array}{l}0.0207 * \\
(0.0024)\end{array}$ \\
\hline Num of Logger if Logger & $\begin{array}{c}-0.0118 * \\
(0.0025)\end{array}$ & $\begin{array}{c}-0.0092 * \\
(0.0025)\end{array}$ & $\begin{array}{c}-0.0125 * \\
(0.0025)\end{array}$ & $\begin{array}{c}-0.0096 * \\
(0.0025)\end{array}$ & $\begin{array}{c}-0.0096 * \\
(0.0025)\end{array}$ \\
\hline $\ln$ (Advertised Rate) & $\begin{array}{l}0.5871 * \\
(0.0028)\end{array}$ & $\begin{array}{c}0.5801 * \\
(0.0029)\end{array}$ & $\begin{array}{l}0.5811 * \\
(0.0029)\end{array}$ & $\begin{array}{l}0.5733 * \\
(0.0029)\end{array}$ & $\begin{array}{l}0.5728 * \\
(0.0030)\end{array}$ \\
\hline Density & $\begin{array}{c}-0.0018 * \\
(0.0003)\end{array}$ & $\begin{array}{c}-0.0025 * \\
(0.0004)\end{array}$ & $\begin{array}{c}-0.0015 * \\
(0.0003)\end{array}$ & $\begin{array}{c}-0.0021 * \\
(0.0003)\end{array}$ & $\begin{array}{c}-0.0019 * \\
(0.0003)\end{array}$ \\
\hline $\ln$ (Volume) & $\begin{array}{l}0.3208 * \\
(0.0035)\end{array}$ & $\begin{array}{l}0.3125 * \\
(0.0036)\end{array}$ & $\begin{array}{l}0.3244 * \\
(0.0035)\end{array}$ & $\begin{array}{l}0.3164 * \\
(0.0036)\end{array}$ & $\begin{array}{l}0.3136 * \\
(0.0035)\end{array}$ \\
\hline $\ln$ (Selling Value) & $\begin{array}{c}-0.0034 \\
(0.0018)\end{array}$ & $\begin{array}{c}-0.0076 * \\
(0.0023)\end{array}$ & $\begin{array}{c}-0.0033 \\
(0.0018)\end{array}$ & $\begin{array}{c}-0.0071 * \\
(0.0023)\end{array}$ & \\
\hline $\ln$ (Manufacturing Costs) & $\begin{array}{l}0.0256 * \\
(0.0035)\end{array}$ & $\begin{array}{l}0.0107 * \\
(0.0039)\end{array}$ & $\begin{array}{l}0.0272 * \\
(0.0035)\end{array}$ & $\begin{array}{l}0.0114 * \\
(0.0039)\end{array}$ & \\
\hline ln (Logging Costs) & $\begin{array}{c}-0.0178 * \\
(0.0034)\end{array}$ & $\begin{array}{l}-0.0035 \\
(0.0037)\end{array}$ & $\begin{array}{c}-0.0189 * \\
(0.0034)\end{array}$ & $\begin{array}{l}-0.0031 \\
(0.0037)\end{array}$ & \\
\hline $\ln$ (Road Costs) & $\begin{array}{c}-0.0038 * \\
(0.0009)\end{array}$ & $\begin{array}{c}-0.0043 * \\
(0.0009)\end{array}$ & $\begin{array}{c}-0.0032 * \\
(0.0009)\end{array}$ & $\begin{array}{c}-0.0037 * \\
(0.0009)\end{array}$ & \\
\hline Salvage Sale Dummy & $\begin{array}{c}-0.0235 * \\
(0.0084)\end{array}$ & $\begin{array}{c}0.0008 \\
(0.0085)\end{array}$ & $\begin{array}{c}-0.0275 * \\
(0.0084)\end{array}$ & $\begin{array}{c}0.0001 \\
(0.0086)\end{array}$ & $\begin{array}{c}0.0014 \\
(0.0086)\end{array}$ \\
\hline Species HHI & $\begin{array}{c}-0.2931 * \\
(0.0134)\end{array}$ & $\begin{array}{c}-0.2632 * \\
(0.0134)\end{array}$ & $\begin{array}{c}-0.2987 * \\
(0.0133)\end{array}$ & $\begin{array}{c}-0.2676 * \\
(0.0133)\end{array}$ & $\begin{array}{c}-0.2661 * \\
(0.0133)\end{array}$ \\
\hline Constant & $\begin{array}{l}2.4237 * \\
(0.0237) \\
\end{array}$ & $\begin{array}{l}2.5789 * \\
(0.0278)\end{array}$ & $\begin{array}{l}2.5078 * \\
(0.0249)\end{array}$ & $\begin{array}{l}2.6566 * \\
(0.0286)\end{array}$ & $\begin{array}{l}2.6654 * \\
(0.0277)\end{array}$ \\
\hline Region Dummies & $\mathrm{N}$ & $\mathrm{Y}$ & $\mathrm{N}$ & $\mathrm{Y}$ & $\mathrm{Y}$ \\
\hline Year Dummies & $\mathrm{N}$ & $\mathrm{N}$ & $\mathrm{Y}$ & $\mathrm{Y}$ & $\mathrm{Y}$ \\
\hline Num of Obs & 33,239 & 33,239 & 33,239 & 33,239 & 33,239 \\
\hline R-squared & 0.8874 & 0.8896 & 0.8888 & 0.8912 & 0.8911 \\
\hline
\end{tabular}

estimate, to get the homogenized bid.

I also allow for unobserved heterogeneity using the technique outlined in Haile, Hong, and Shum (2003). The concern is that increased auction participation due to unobserved factors that also increase valuations, may be interpreted as externalities. If the effect the unobserved characteristics have on auction participation and bidder valuations is the same across bidders of different types, then this would not interfere with the identification of the externality parameters, since externalities 
are identified off of how bidders of a given type respond differently to increased competition from bidders of different types. However if the unobserved factors have a different effect on mills then they do on loggers, then there is concern that the estimated externalities will be biased if unobserved heterogeneity is not taken into account.

To account for unobserved heterogeneity I use an instrumental variables approach where I use the number of potential bidders of each type as instruments for the actual number of auction participants of each type. I define the number of potential bidders for each auction as the number of firms of each type, who participated in an auction in the same county, within the previous year, as the auction of interest. I then use variation in the number of potential bidders rather than variation in the number of actual bidders, to estimate the externality parameters.

I estimate the externalities using each of the three approaches outlined above: the median estimator, the mean estimator, and the K-S estimator. For the choice of kernel and bandwidths I use the same kernel and bandwidths outlined in the Monte Carlo section. I also use the same trimming procedure as I used there. To get standard errors I use a bootstrap method.

\subsection{Results}

Initially I only allow for externalities to exist between two mill bidders and between two logger bidders. The estimation results for each of the three methods are in Table 6. Across all three methods one can see that there is a considerable externality imposed upon mill bidders by other mill bidders. The parameter estimates indicate that because of competition outside the auction, a mill bidder winning the auction will cost a rival mill by between $10.4 \%-18.2 \%$ of the residual portion of their valuation for the timber. ${ }^{16}$ Ostensibly this is due to the competition between mill bidders in the downstream lumber market.

Table 6: Externality Parameter Results: Mills and Loggers

\begin{tabular}{|c|c|c|c|c|c|c|}
\hline & \multicolumn{2}{|c|}{ Median } & \multicolumn{2}{c|}{ Mean } & \multicolumn{2}{c|}{ KS } \\
\hline \multirow{4}{*}{ Mill-Mill } & $\begin{array}{c}\text { Ignore } \\
\text { Unob. Het. }\end{array}$ & $\begin{array}{c}\text { Account for } \\
\text { Unob. Het. }\end{array}$ & $\begin{array}{c}\text { Ignore } \\
\text { Unob. Het. }\end{array}$ & $\begin{array}{c}\text { Account for } \\
\text { Unob. Het. }\end{array}$ & $\begin{array}{c}\text { Ignore } \\
\text { Unob. Het. }\end{array}$ & $\begin{array}{c}\text { Account for } \\
\text { Unob. Het. }\end{array}$ \\
& 0.1822 & 0.1463 & 0.1595 & 0.1311 & 0.1041 & 0.1401 \\
& $(0.0232)$ & $(0.0318)$ & $(0.0375)$ & $(0.0729)$ & $(0.0459)$ & $(0.0466)$ \\
& & & & & & \\
Log-Log & 0.0779 & 0.0505 & 0.0570 & 0.0485 & -0.0246 & -0.0977 \\
& $(0.0465)$ & $(0.0707)$ & $(0.0462)$ & $(0.0997)$ & $(0.0280)$ & $(0.0231)$ \\
\hline
\end{tabular}

\footnotetext{
${ }^{16} \mathrm{By}$ valuation residual I mean the portion of the firm's valuation that is not due to the observed auction characteristics. Particularly bidder valuations can be decomposed as $\ln \left(v_{j}\right)=\beta x_{a}+\ln \left(\epsilon_{j}\right)$, where $j$ indexes bidders, $a$ indexes auctions, and $x_{a}$ are the observable characteristics of auction $a$. Then the externality effect I am estimating is the effect an additional bidder of a given type has on $\ln \left(\epsilon_{j}\right)$.
} 
The externality effect of downstream competition could affect the allocation of timber if the highest bids are not coming from firms with the highest valuation for the timber, but instead from mills that are bidding high to keep the tract away from rival mills. Using the median estimator that accounts for unobserved heterogeneity, I find that in $4.21 \%$ of the timber auctions in my sample, the presence of externalities made it so that the timber tract was not won by and allocated to, the highest value bidder. The characteristics of these auctions in which the highest value bidder did not win, are in Table 7.

On average, auctions where the timber tract was misallocated to a bidder that did not have the highest value for the tract, had more bidders, especially more mill bidders, than the average auction. This supports the story that as more mills entered the auction, concerns that a downstream mill competitor would win the timber tract, and thus have a stronger position in the lumber market, increased. This then led these mill bidders to increase their bids to the point that sometimes the bidder with the highest valuation did not win the tract. Table 8 further shows that in this subset of auctions where the highest value bidder did not win the tract, that the highest bidder was often a mill while the bidder with the highest valuation was often a logger. This illustrates that when the externality effect was large enough to affect the allocation of the timber, it was often the case that timber was sub-optimally acquired by mills at the expense of loggers that had a higher valuation for the timber.

Table 7: Characteristics of auctions in which highest value bidder did not win because of the presence of externalities, compared with characteristics of auctions where the highest value bidder did win.

\begin{tabular}{|c|c|c|}
\hline & $\begin{array}{c}\text { Auctions Not Won } \\
\text { By Bidder With } \\
\text { Highest Value }\end{array}$ & $\begin{array}{c}\text { Auctions Won } \\
\text { By Bidder With } \\
\text { Highest Value }\end{array}$ \\
\hline Count & 371 & 8431 \\
Ave Num Bidders & 4.76 & 3.62 \\
Ave Num Mills & 2.85 & 1.98 \\
Ave Num Loggers & 1.79 & 1.61 \\
\hline
\end{tabular}

Table 8: Subset of auctions in which the highest value bidder did not win

\begin{tabular}{|c|c|c|}
\hline & Highest Bidder & Highest Value \\
\hline Mills & 253 & 147 \\
Loggers & 118 & 221 \\
Small Business & 0 & 3 \\
\hline
\end{tabular}

To illustrate how not accounting for externalities can affect estimates for valuation distributions, I compared the distribution of valuations that I get using my technique that accounts for externalities with the typical technique of Guerre, Perrigne, and Vuong (2000), which does not take externalities into account. The graph of the estimated cumulative distribution functions for both mills and loggers 
in both cases are given in Figure 4. The graph on the left is the estimated distribution of valuations when externalities are taken into account, while the graph on the right is the estimated distribution when externalities are ignored.

Figure 4: Estimated Distribution of Logarithm of Valuation Residuals
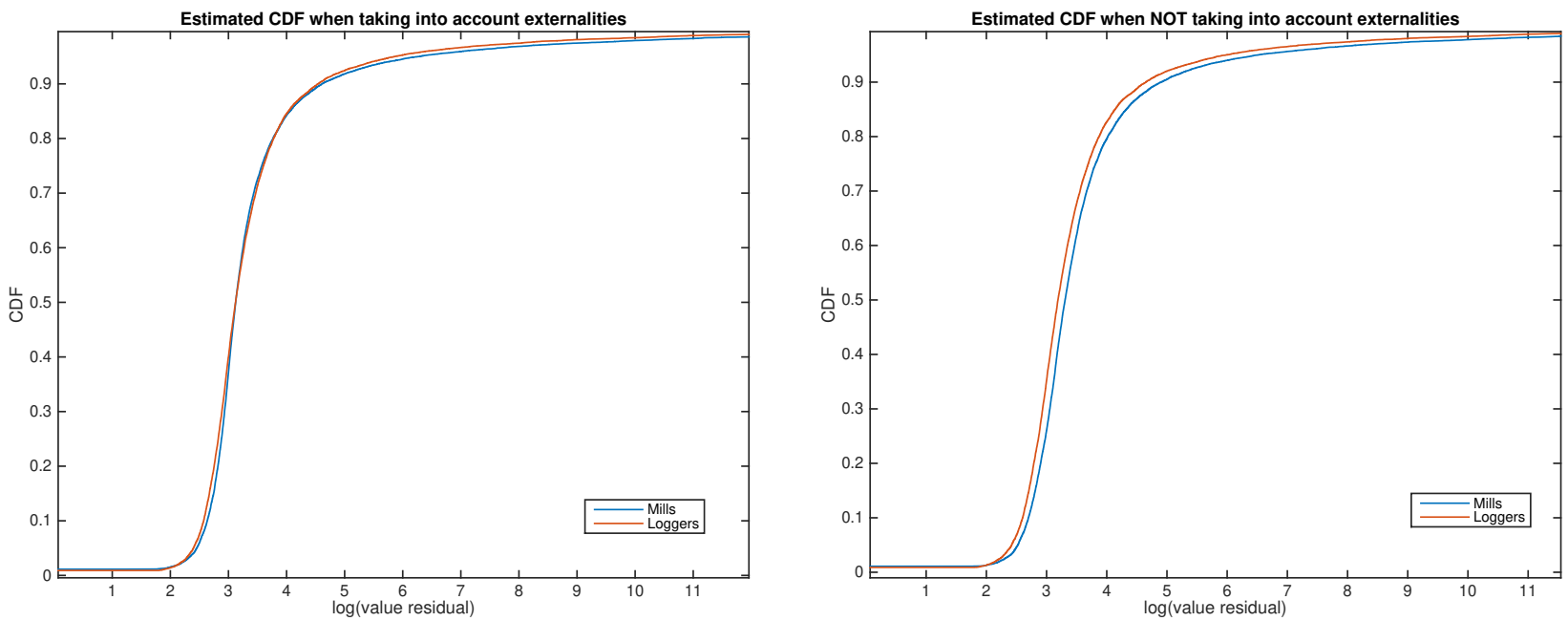

In the graph on the right, the mill bidders' valuation distribution stochastically dominates the logger bidders' valuation distribution. But on the graph on the left there is no stochastic dominance. This shows that if externalities are not accounted for, then when estimating bidder valuation distributions using the usual structural auction estimation techniques, it will appear as if mill bidders have higher valuations for timber tracts then their logger counterparts. My estimation results offer a different story for why mill bidders bid higher than logger bidders, and it is that mill bidders bid higher in certain auctions to keep the item away from other mill bidders with whom they compete in the downstream lumber market. I can separate this from the asymmetric distributions explanation, because my estimation technique compares mill bids in auctions where they face more competition from other mills, with mill bids where they face more competition from other loggers, and I find that mills are on average only increasing their bids when facing more mills and not when facing more loggers. This is evidence that the higher bids placed by mills is due to externalities from outside competition between mills rather than asymmetries in the valuation distributions between mills and loggers.

Finally I further broken down mills into two types: small mills and large mills, based on SBA size classification standards. I then estimated the same model as before but looked for externalities between the different types of mills, and ignored externalities between loggers. The results are in Table 9. Standard errors here are much larger than in the base case, and there is less similarity 
Table 9: Externality Parameter Results: Small Mills and Large Mills

\begin{tabular}{|c|c|c|c|c|c|c|}
\hline & \multicolumn{2}{|c|}{ Median } & \multicolumn{2}{c|}{ Mean } & \multicolumn{2}{c|}{ KS } \\
\hline & $\begin{array}{c}\text { Ignore } \\
\text { Unob. Het. }\end{array}$ & $\begin{array}{c}\text { Account for } \\
\text { Unob. Het. }\end{array}$ & $\begin{array}{c}\text { Ignore } \\
\text { Unob. Het. }\end{array}$ & $\begin{array}{c}\text { Account for } \\
\text { Unob. Het. }\end{array}$ & $\begin{array}{c}\text { Ignore } \\
\text { Unob. Het. }\end{array}$ & $\begin{array}{c}\text { Account for } \\
\text { Unob. Het. }\end{array}$ \\
\hline \multirow{2}{*}{ Small Mill - Small Mill } & 0.2031 & 0.1204 & 0.3206 & 0.2802 & 0.0813 & 0.0228 \\
& $(0.0372)$ & $(0.0381)$ & $(0.0426)$ & $(0.2230)$ & $(0.0593)$ & $(0.1156)$ \\
Small Mill - Large Mill & 0.3579 & 0.3358 & 0.3321 & 0.3135 & 0.2144 & 0.2195 \\
& $(0.0546)$ & $(0.0611)$ & $(0.1001)$ & $(0.2560)$ & $(0.1040)$ & $(0.0975)$ \\
Large Mill - Small Mill & -0.0504 & -0.0092 & -0.0677 & -0.0766 & -0.0974 \\
Large Mill - Large Mill & $(0.0847)$ & $(0.0873)$ & $(0.1845)$ & $(0.1739)$ & $(0.0922)$ & $(0.2987)$ \\
& 0.1207 & 0.0602 & 0.1571 & 0.0670 & 0.1810 & $(0.1224)$ \\
$(0.1715)$ & $(0.1799)$ & $(0.1601)$ & $(0.1945)$ & $(0.2786)$ \\
\hline
\end{tabular}

between the three different estimators. Still one can infer from the parameter estimates that the most affected firms are small mills, and that they are most affected by large mill competitors. On the other hand, large mills don't appear to be affected by outside competition, illustrating that the externality effect derived in the base case is mainly driven by the effect downstream competition has on the bidding behavior of small firms. This is most likely a result of timber auctions being local in nature, so that bidding behavior is most affected by local downstream competition. Small mills are more concerned with local competition than are large mills, whom garner most of their revenue from the global lumber market. Thus it is local downstream competition, which disproportionately affects small mills compared to other bidder types, which affects bidding in timber auctions, as these small mill bidders attempt to keep timber tracts away from their downstream competitors in the local lumber market.

\section{Conclusion}

This paper studies the question of how downstream competition between bidders affects bidding strategies and auction outcomes. This is done by introducing a simple auction model with externalities and establishing the identification and estimation of such a model. Three different estimators for the externalities are introduced, and Monte Carlo results show that the estimators perform relatively well in a simple setting with two bidder types.

I then apply the identification and estimation strategy to the case of USFS timber auctions, a setting where there have recently been antitrust allegations accusing a mill bidder of raising their bid in order to keep timber away from competitors and affect the downstream lumber market. I find that between 1982 and 1990, downstream competition between mills was strong enough that a rival mill acquiring a timber tract, cost a mill bidder by between $10 \%$ to $18 \%$ of the heterogeneous portion of the mill bidder's valuation of the tract. There was no such effect from an additional logger entering 
the auction. This indicates that mills bid higher in timber auctions in order to keep the timber away from other mill competitors, and helps to explain the observation that mills generally bid higher than loggers, which was previously explained as stochastic dominance of the mill valuation distribution over the logger valuation distribution. Furthermore I find that these externality effects lead in $4.2 \%$ of the auctions in my sample, to the auctioned off timber tract being misallocated to a bidder that does not have the highest valuation for the tract.

The model of this paper can be extended in a variety of ways including the case where the externality that a bidder imposes on a rival is correlated with their private valuation for the object. In such a case the externality value is a bidder-pair-specific, $\alpha_{i_{k} j_{k^{\prime}}}$, and is private information to the imposer of the negative externality, bidder $j_{k^{\prime}}$. This is the case in the original auctions with externalities model of Jehiel, Moldovanu, and Stacchetti (1996) where $\alpha_{i_{k} j_{k^{\prime}}}$ and $v_{j_{k^{\prime}}}$ are allowed to be correlated. In particular, I will assume a specific form of the correlation in that $\alpha_{i_{k} j_{k^{\prime}}}=\alpha_{k k^{\prime}} v_{j_{k^{\prime}}}$ for some types-specific parameter $\alpha_{k k^{\prime}}$. As far as I know the estimation strategy only extends to this particular form of correlation.

Jehiel, Moldovanu, and Stacchetti (1996) provide some arguments on why it makes sense in a variety of examples for $\alpha_{i_{k} j_{k^{\prime}}}$ to be private information and to be correlated with $v_{j_{k^{\prime}}}$. The particular form of correlation that I impose is a result of applying Cournot competition to the downstream market, where the auction is for some good that lowers the winning firm's marginal cost. The parameter $\alpha_{k k^{\prime}}$ is then a combination of the parameters from the Cornout model. This is shown in the Appendix for the case of 2 bidders.

Estimation of the parameters in this case follows the same strategy as before, except that the equation relating bidder valuations to bids is different. Instead of equation (9), I get its counterpart:

$$
v_{i_{k}}=\frac{H_{k}(b \mid \mathbb{B})+b H_{k}^{\prime}(b \mid \mathbb{B})}{H_{k}^{\prime}(b \mid \mathbb{B})+\sum_{k^{\prime}} \sum_{j \in \mathbb{B}_{k^{\prime}}}\left[\alpha_{k k^{\prime}} \operatorname{Pr}\left(\max _{l \neq i, j \in B} b_{l} \leq b \mid \mathbb{B}\right) g_{j}(b \mid \mathbb{B})\right]}
$$

I can then use this equation in the same way as I used equation (9) to identify and estimate $\alpha_{k k^{\prime}}$.

Another extension to the model is to have the externality depend on a set of covariates. In this case one would let $\alpha_{k k^{\prime}}=\beta_{1}^{\prime} X_{k}+\beta_{2}^{\prime} X_{k^{\prime}}$, where $X_{k}$ and $X_{k^{\prime}}$ are vectors of variables measuring characteristics of the type $k$ and $k^{\prime}$ firms respectively, and $\left\{\beta_{1}, \beta_{2}\right\}$ are the parameters to be estimated. This would allow one to measure the effect certain characteristics have on the size of the externality.

There are also many applications where data on all the bids is not available and instead one can only observe the winning bid in each auction. For instance when thinking of professional sports and auctions for players, while many different teams may bid on a player, only the winning bid, the actual salary the player receives, is observable. This is also true of many other potential applications, where 
usually all that is observed is the transaction price and the identities of the participants in the market. In such a setting, obtaining estimates for $\alpha$, and the distributions $F_{k}(\cdot)$, is still possible.

Everything is the same as before except now for each auction $t$, I only observe the winning bid, $b^{w t}$, the identify of the winning bidder, $w^{t}$, and the number of bidders of each type participating in the auction, $n_{k}^{t}$ for $k=1, \ldots, K$. I still want to use equation (9) to identify and estimate the externality parameters, but now I no longer directly observe $H_{k}(\cdot \mid \mathbb{B})$, as well as the other densities and distributions, in the data. These densities and distributions depend on all participants' distribution of bids, while I only observe the distribution of the winning bid. What is necessary is some kind of relation between the distribution of the winning bid and the distribution of bids in general.

Following Brendstrup and Paarsch (2003) and Prakasa Rao (1992), I get the following equation relating a bidder of type $k$ 's bid distribution, $G_{k}(b \mid \mathbb{B})$, to the observed distributions of winning bids for bidders of different types, $G_{k}^{w}(b \mid \mathbb{B})$ :

$$
G_{k}(b \mid \mathbb{B})=\exp \left\{\int_{-\infty}^{b} \frac{1}{\sum_{k^{\prime}=1}^{K}\left(G_{k^{\prime}}^{w}(s \mid \mathbb{B})\right)^{n_{k^{\prime}}}} \mathrm{d} G_{k}^{w}(s \mid \mathbb{B})\right\}
$$

where $G_{k}^{w}(b \mid \mathbb{B})=\operatorname{Pr}\left(b_{i_{k}} \leq b, b_{i_{k}} \geq b_{j} \forall j \in \mathbb{B} \mid \mathbb{B}\right)$ and $G_{k}(b \mid \mathbb{B})=\operatorname{Pr}\left(b_{i_{k}} \leq b \mid \mathbb{B}\right)$. Note that $G_{k}^{w}(b \mid \mathbb{B})$ is the joint probability that a bidder of type $k$ wins the auction and that their bid is less then $b$. An intuitive proof of this result from Prakasa Rao (1992) can be found in Brendstrup and Paarsch (2003), and is repeated here in the Appendix. Equation (32) will allow me to use the observations on the winning bid and the winner's type, to get a distribution of bids that can then be used to calculate the other distributions from equation (9). For example for $H_{k}(b \mid \mathbb{B})$ :

$$
H_{k}(b \mid \mathbb{B})=G_{k}(b \mid \mathbb{B})^{n_{k}-1} *\left(\prod_{l \neq k} G_{l}(b \mid \mathbb{B})^{n_{l}}\right)
$$

The other distributions from equation (9) can also be calculated similarly from $G_{k}(b \mid \mathbb{B})$, and thus I can once again evaluate the equation to get pseudo-values that depend linearly on $\alpha$. From there identification and estimation then follow straightforwardly from the case when all the bids are observed.

\section{References}

[1] Aradillas-Lopez A, Gandhi A, Quint D. 2013. Identification and Inference in Ascending Auctions with Correlated Privates. Econometrica 81(2): 489-534.

[2] Athey S, Haile PA. 2002. Identification of Standard Auction Models. Econometrica 70: 21072140.

[3] Athey S, Haile, PA. 2007. Nonparametric Approaches to Auctions. In Handbook of Econometrics, Vol. VI, Heckman J, Leamer E (eds). North-Holland: Amsterdam; 3849-3965. 
[4] Athey S, Levin J, Seira E. 2011. Comparing Open and Sealed Bid Auctions: Evidence from Timber Auctions. The Quarterly Journal Economics 126: 207-257.

[5] Balat, J. 2013. Highway Procurement and the Stimulus Package: Identification and Estimation of Dynamic Auctions with Unobserved Heterogeneity. Working Paper, John Hopkins University.

[6] Baldwin L, Marshall R, Richard J. 1997. Bider Collusion at U.S. Forest Service Timber Auctions. Journal of Political Economy 105: 657-699

[7] Brandt F, Sandholm T, Shoham Y. 2007. Spiteful Bidding in Sealed-Bid Auctions. International Joint Conference on Artificial Intelligence, Hyderabad, India.

[8] Brendstrup B, Paarsch, H. 2003. Nonparametric Estimation of Dutch and First-Price, Sealed-bid Auction Models with Asymmetric Bidders. Working Paper, University of Iowa.

[9] Campo S, Perrigne I, Vuong Q. 2003. Asymmetry in First-Price Auctions with Affiliated Private Values. Journal of Applied Econometrics 18: 179-207.

[10] Cummins JG. 1994. Investment Under Uncertainty: Estimates from Panel Data on Pacific northwest Forest Products Firms. Working Paper, Columbia University.

[11] Das Varma G. 2002. Standard Auctions with Identity-Dependent Externalities. The RAND Journal of Economics 33: 689-708.

[12] Elyakime B, Laffont J, Loisel P, Vuong Q. 1994. First-Price Sealed-Bid Auctions with Secret Reserve Prices. Annales d'Economie et Statistiques 34: 115-141.

[13] Flambard V, Perrigne I. 2006. Asymmetry in Procurement Auctions: Evidence from Snow Removal Contracts. The Economic Journal 116: 1014-1036.

[14] Foote J, Rausser G.C. 2007. Monopsony and Predatory Bidding in the Lumber Industry: The Weyerhaeuser Case. The Antitrust Revolution, edited by L. White and J.L. Kwoka (6th edition). New York: Oxford University Press (2013).

[15] Gillen B. 2010. Identification and Estimation of Level-k Auctions. Working Paper, California Institution of Technology.

[16] Groeger J.R. 2014. A Study of Participation in Dynamic Auctions. International Economic Review 55: 1129-1154.

[17] Guerre E, Perrigne I, Vuong Q. 2000. Optimal Nonparametric Estimation of First-Price Auctions. Econometrica 68: 525-574.

[18] Guerre E, Perrigne I, Vuong Q. 2009. Nonparametric Identification of Risk Aversion in First-Price Auctions Under Exclusion Restrictions. Econometrica 77: 1193-1227.

[19] Haile P. 2001. Auctions with Resale Markets: An Application to U.S. Forest Service Timber Sales. American Economic Review 91(3): 399-427.

[20] Haile P, Hong H, Shum M. 2003. Nonparametric Tests for Common Values at First-Price Sealed Bid Auctions. NBER Working Paper.

[21] Haile P, Tamer E. 2003. Inference with an Incomplete Model of English Auctions. Journal of Political Economy 111: 1-52.

[22] Jehiel P, Moldovanu B. 1996. Strategic Nonparticipation. The RAND Journal of Economics 27: 84-98.

[23] Jehiel P, Moldovanu B. 2000. Auctions with Downstream Interaction Among Buyers. The RAND Journal of Economics, 31: 768-791.

[24] Jehiel P, Moldovanu B, Stacchetti E. 1996. How (Not) to Sell Nuclear Weapons. The American Economic Review, 86: 814-829. 
[25] Jehiel P, Moldovanu B, Stacchetti E. 1999. Multidimensional Mechanism Design for Auctions with Externalities. Journal of Economic Theory 85: 258-293.

[26] Jeziorski P, Krasnokutskaya E. 2014. Dynamic Auction Environment with Subcontracting. Working Paper, John Hopkins University.

[27] Jofre-Bonet, M, Pesendorfer, M. 2014. Optimal Sequential Auctions. International Journal of Industrial Organization 33: 61-71.

[28] Levine D. 1998. Modeling Altruism and Spitefulness in Experiments. Review of Economic Dynamics 1: 593-622.

[29] Li T, Perrigne I, Vuong Q. 2002. Structural Estimation of the Affiliated Private Value Auction Model. The RAND Journal of Economics 33: 171-193.

[30] Lu J, Perrigne I. 2008. Estimating Risk Aversion from Ascending and Sealed-Bid Auctions: The Case of Timber Auction Data. Journal of Applied Econometrics 23: 871-896.

[31] Marshall RC, Meurer MJ. 1994. Numerical Analysis of Asymmetric First Price Auctions. Games and Economic Behavior 7: 193-220.

[32] McAdams D. 2003. Monotone Equilibrium in Multi-Unit Auctions. MIT Sloan Working Paper.

[33] Morgan J, Reis G, Steiglitz K. 2003. The Spite Motive and Equilibrium Behavior in Auctions. Contributions to Economic Analysis 8 Policy 2(1): 1102-1127.

[34] Paarsch HJ. 1997. Deriving an Estimate of the Optimal Reserve Price: An Application to British Columbian Timber Sales. Journal of Econometrics 78(2): 333-357.

[35] Prakasa Rao BLS. 1992. Identifiability in Stochastic Models: Characterization of Probability Distributions. Boston Academic Press: Boston, MA.

[36] Reny PJ, Zamir S. 2004. On the Existence of Pure Strategy Monotone Equilibria in Asymmetric First-Price Auctions. Econometrica 72(4): 1105-1125.

[37] Seim K. 2006. An Empirical Model of Firm Entry with Endogenous Product-Type Choices. The RAND Journal of Economics, 37: 619-640. 


\section{A Appendix: Three Motivating Examples of Models of Out- side Competition}

The following subsections present three motivating examples of different models of market competition that fit into the auction model with externalities framework of this paper.

\section{A.1 Mergers and Acquisitions}

In a merger acquisition, firms bid on the target firm, with the bidder with the largest bid acquiring the target. Bidders for these acquisitions are generally firms that compete against each other in the market for some product. Market competition between the firms may depend on how similar or differentiated their products are, how large or small they are relative to each other, or whether they are an entrant or already an incumbent in the target's market. This can affect how these firms will bid to acquire the target if their downstream profits are affected differently depending on the eventual acquirer if it is not them.

The model I have in mind is an entry model similar to Seim (2006), where firms own multiple stores in a market and by making an acquisition of store $l$ in market $m$, firm $i$ gains profit:

$$
\pi_{i m l}=\beta X_{m}+\delta B_{i m}+\sum_{b} \gamma_{b} N_{b m}+\epsilon_{i m l}
$$

where $X_{m}$ are market characteristics, $B_{i m}$ is the number of stores firm $i$ already has in market $m$, $N_{b m}$ is the number of competing firms with $b$ stores in market $m$, and $\epsilon_{i m l}$ is the idiosyncratic profit of target store $l$. The idiosyncratic value of the target to firm $i, \epsilon_{i m l}$, is private information to firm $i$. As described in Seim (2006), this private error term captures all the differences between the firm and its rivals. Thus with such a model it is reasonable to think of $\epsilon_{i m l}$ as private information while the rest of the model components are common knowledge due to the symmetry of these components across different firms. This type of model would make sense in a market such as banking, where firms acquire multiple branches in a single market to boost profits.

The competition effect from rival firms is based on the rivals' size, which here is captured by the number of stores they have in the market, $b$. A firm's valuation from making the acquisition is then given by $v_{i}=\pi_{i m l}$, which is private information because $\epsilon_{i m l}$ is private information. If a firm that initially had $b$ stores in the market, wins the auction, then the profit for all other stores will fall by $\gamma_{b+1}-\gamma_{b}$. Thus the externality for a firm that initially had $b^{\prime}$ stores, would be $\alpha_{b^{\prime} b}=b^{\prime}\left(\gamma_{b+1}-\gamma_{b}\right)$.

The externality $\alpha_{b^{\prime} b}$ captures the idea that firm profits may be affected differently depending on the market presence of the rival firm making the acquisition. Large firms with many current stores may 
care more about another large firm making the acquisition then if a smaller firm with only one current store, acquires the target. Estimation and identification of the model will look at how acquisition bid values differ based on how much downstream competition the bidder faces from the other bidders making serious offers, and will use that to identify how large of an effect market competition between bidding firms has on the bids submitted in a merger and acquisition and the ultimate acquisition price of the target.

\section{A.2 License Auctions}

In the bidding for licenses (or contracts or landing slots), the value of the acquisition depends on the number of licenses (or contracts or landing slots) held by competitors, and also the degree of rivalry between those firms in the downstream market. In bidding for government contracts or licenses, the degree of rivalry could be based on geographic regions. Thus firm types $k$ would be based on what geographic market they compete in. I would expect in this case for $\left|\alpha_{k k}\right|>\left|\alpha_{k k^{\prime}}\right|$ (meaning externality effects are larger from bidders of the same type than from bidders of different types) since firms generally are more competitive with their counterparts from the same geographic market. In the competition for airline slots, bidders could be partitioned into groups based on flying to similar locations, and again I would expect stronger externality effects from bidders of the same type.

More explicitly, a firm of type $k$ would have their profit depend on the number of licenses they own, and the number of licenses their competitors own, $\pi_{k}\left(l_{i_{k}} ; l_{1}, \ldots, l_{K}\right)$. If firm $i_{k}$ wins the auction for the license, their profit will change by $\pi_{k}\left(l_{i_{k}}+1 ; l_{1}, \ldots, l_{K}\right)-\pi_{k}\left(l_{i_{k}} ; l_{1}, \ldots, l_{K}\right)=v_{i_{k}}$. If a firm of type $k^{\prime}$ wins the auction, then firm $i_{k}$ 's profit will change by $\pi_{k}\left(l_{i_{k}} ; l_{1}, \ldots, l_{k^{\prime}}+1, \ldots, l_{K}\right)-$ $\pi_{k}\left(l_{i_{k}} ; l_{1}, \ldots, l_{k^{\prime}}, \ldots, l_{K}\right)=-\alpha_{k k^{\prime}}$. The profit function could even have a parametric form such as $\pi_{k}\left(l_{i_{k}} ; l_{1}, \ldots, l_{K}\right)=\beta_{O} l_{i_{k}}+\sum_{k^{\prime}} \beta_{k k^{\prime}} l_{k^{\prime}}+\epsilon_{k}\left(l_{i_{k}}\right)$, where $\epsilon_{k}\left(l_{i_{k}}\right)$ is private information to firm $i_{k}$. Then the value of winning the auction for a bidder of type $k$ would be $v_{i_{k}}=\beta_{O}+\epsilon_{k}\left(l_{i_{k}}+1\right)-\epsilon_{k}\left(l_{i_{k}}\right)$ and the externality suffered if a bidder of type $k^{\prime}$ won the auction would be $\alpha_{k k^{\prime}}=-\beta_{k k^{\prime}}$. Here it is again reasonable to think of $v_{i_{k}}$ as private information since a license provides an idiosyncratic increase to firm profit that is specific to firm $i_{k}$.

Again the externality $\alpha_{k k^{\prime}}$ captures the type-dependent nature of the acquirer's effect on competitor profits. A firm's profits may be affected more by an increase in licenses by a rival of the same type, then a rival of a different type that they do not compete as heavily with. Identification and estimation will then look at how bidding on these licenses or contracts is affected by the identities of the rival bidders. Recovery of the externality parameters will provide information on how a particular firm acquiring a license affects each of their rivals differently depending on how much they compete outside of the auction market, and will provide information about how acquiring licenses affects market competition. 


\section{A.3 Cournot Competition in Downstream Market}

Finally an extension to this model (which is discussed in Section 6) can apply to an auction where the bidders compete in a downstream market of Cournot competition. Assume bidders compete in the outside market for some good whose price is determined by the equation:

$$
p=d_{0}-\sum_{k=1}^{K}\left(d_{k} *\left(\sum_{i \in \mathbb{B}_{k}} Q_{i}\right)\right)
$$

where $Q_{i}$ is the quantity of the good produced by firm $i$ and $\left\{d_{0}, d_{1}, \ldots, d_{K}\right\}$ are parameters. Each firm then chooses quantity to maximize their profit, $\pi_{i}=\left(p-c_{i}\right) Q_{i}$, where $c_{i}$ is the firm- $i$ specific marginal cost of production, which is assumed to be common knowledge.

The auction is then for some innovation to production that will lower the marginal costs of production for the winning bidder by some amount, which is private information to the bidder. By solving the Cournot model, one can then get the value of winning the auction in terms of the Cournot model parameters, the original firm marginal costs, and the value of the innovation for the winning firm (how much it reduces the winning firm's marginal cost). This is the bidder valuation, $v_{i_{k}}$, in the above auction model. Additionally, one can get the the change in profits for each losing bidder in the auction, also as a function of the Cournot model parameters, the original firm marginal costs, and the value of the innovation for the winning firm. This value would then be the externality $\alpha_{i_{k} j_{k^{\prime}}}$.

I show here how these values can be derived for the case of 2 bidders. Assume there are two firms of different types in a market characterized by Cournot competition. The equilibrium price of the good is affected by the quantities produced by each firm, and is given by:

$$
p=d_{0}-d_{1} Q_{1}-d_{2} Q_{2}
$$

where $\left\{d_{0}, d_{1}, d_{2}\right\}$ are parameters. Each firm $i$ has an idiosyncratic marginal cost, $c_{i}$ of producing the good, and they each choose quantity to maximize their profit, $\pi_{i}=\left(p-c_{i}\right) Q_{i}$. Solving the model gives:

$$
\pi_{i}=\frac{1}{9 d_{i}}\left(d_{0}-2 c_{i}+c_{j}\right)^{2}
$$

Now assume the two firms participate in an auction for a cost-reducing mechanism that reduces their marginal cost by amount $\epsilon_{i}$, which is private information to firm $i$. Then the value of winning the auction for firm $i$ is:

$$
v_{i}=\frac{1}{9 d_{i}}\left(4 \epsilon_{i}\left(d_{0}-2 c_{i}+c_{j}+\epsilon_{i}\right)\right)
$$


and the externality suffered by $i$ if $j$ wins the auction is:

$$
\alpha_{i j}=\frac{1}{9 d_{i}}\left(4 \epsilon_{j}\left(d_{0}-2 c_{i}+c_{j}-\epsilon_{j}\right)\right)
$$

Note that in this case the externality depends on the winning bidder's private value, and is thus also private information as well. In particular the externality would depend on bidder valuations through $\alpha_{i_{k} j_{k^{\prime}}}=\alpha_{k k^{\prime}} * v_{j_{k^{\prime}}}$, where $\alpha_{k k^{\prime}}$ is the externality parameter I am looking to estimate that is a function of the parameters and marginal costs of the Cournot model. This correlation between the externality and the winning bidder's private value makes sense in many other situations where the

larger the value of the object for firm $j$, the larger will be the negative impact on rival firm $i$ 's profits in the downstream market. Extending the model to this setting where externalities are identitydependent (rather than type-dependent) and are private information is relatively straightforward and such an extension is discussed in the conclusion of this paper. Estimating such a model allows one to infer how commonly understand measures of competition between firms, as given by the parameters of a Cournot model of competition, affect bidding behavior in an auction model. Also given that a researcher only has data on the outcomes of auctions for some item that reduces competing firms' marginal costs, the framework of this paper can be used to identify the degree of price competition between the firms (through easily interpreted Cournot parameters) based on how bids differ based on the identities of rival auction participants.

\section{B Appendix: Derivations/Proofs}

\section{B.1 Derivation of Equation (6)}

I want to get:

$$
\int_{\underline{b_{k^{\prime}}(\mathbb{B})}}^{\overline{b_{k^{\prime}}(\mathbb{B})}} H_{k^{\prime}}\left(x \mid b_{i_{k}}=b, \mathbb{B}\right) g_{k^{\prime}}(x \mid \mathbb{B}) \mathrm{d} x=\int_{b}^{\overline{b_{k^{\prime}}(\mathbb{B B})}} \operatorname{Pr}\left(\max _{l \neq i_{k}, j_{k^{\prime}} \in B} b_{l} \leq x \mid \mathbb{B}\right) g_{k^{\prime}}(x \mid \mathbb{B}) \mathrm{d} x
$$

I will first write out $H_{k^{\prime}}\left(x \mid b_{i_{k}}=b, \mathbb{B}\right)$ as:

$$
H_{k^{\prime}}\left(x \mid b_{i_{k}}=b, \mathbb{B}\right)=\frac{\operatorname{Pr}\left(\max _{l \in B_{-j_{k^{\prime}}}} b_{l} \leq x, b_{i_{k}}=b \mid \mathbb{B}\right)}{\operatorname{Pr}\left(b_{i_{k}}=b \mid \mathbb{B}\right)}
$$


Then simplifying the numerator I get:

$$
\begin{aligned}
\operatorname{Pr}\left(\max _{l \in B_{-j_{k^{\prime}}}} b_{l} \leq x, b_{i_{k}}=b \mid \mathbb{B}\right) & =\operatorname{Pr}\left(\max _{l \neq i_{k}, j_{k^{\prime}} \in B} b_{l} \leq x, b_{i_{k}} \leq x, b_{i_{k}}=b \mid \mathbb{B}\right) \\
& =\operatorname{Pr}\left(\max _{l \neq i_{k}, j_{k^{\prime}} \in B} b_{l} \leq x \mid \mathbb{B}\right) \operatorname{Pr}\left(b_{i_{k}} \leq x, b_{i_{k}}=b \mid \mathbb{B}\right) \\
& =\operatorname{Pr}\left(\max _{l \neq i_{k}, j_{k^{\prime}} \in B} b_{l} \leq x \mid \mathbb{B}\right) \operatorname{Pr}\left(b_{i_{k}} \leq x \mid b_{i_{k}}=b, \mathbb{B}\right) \operatorname{Pr}\left(b_{i_{k}}=b \mid \mathbb{B}\right) \\
& =\operatorname{Pr}\left(\max _{l \neq i_{k}, j_{k^{\prime}} \in B} b_{l} \leq x \mid \mathbb{B}\right) \mathbf{1}\{b \leq x\} \operatorname{Pr}\left(b_{i_{k}}=b \mid \mathbb{B}\right)
\end{aligned}
$$

where $\mathbf{1}\{\cdot\}$ is the indicator function. Equality (59) follows from the independence of valuations and thus bids, and (60) from Bayes' rule. Thus I can write out $H_{k^{\prime}}\left(x \mid b_{i_{k}}=b, \mathbb{B}\right)$ as:

$$
\begin{aligned}
H_{k^{\prime}}\left(x \mid b_{i_{k}}=b, \mathbb{B}\right) & =\operatorname{Pr}\left(\max _{l \neq i_{k}, j_{k^{\prime}} \in B} b_{l} \leq x \mid \mathbb{B}\right) \mathbf{1}\{b \leq x\} \\
& = \begin{cases}\operatorname{Pr}\left(\max _{l \neq i_{k}, j_{k^{\prime}} \in B} b_{l} \leq x \mid \mathbb{B}\right) & \text { if } b \leq x \\
0 & \text { if } b>x\end{cases}
\end{aligned}
$$

From here it is easy to see how equation (6) follows.

\section{B.2 Proof of Proposition 1}

Assume bidder participation is exogenous (i.e. $\left.F_{k}(\cdot ; \mathbb{B})=F_{k}\left(\cdot ; \mathbb{B}^{a}\right), \forall \mathbb{B}, \mathbb{B}^{a}\right)$ and that inverse bid function $\xi_{k}(b, G ; \alpha, \mathbb{B})$ is strictly increasing in $b$ for $b \in\left[\beta_{k}\left(\underline{v_{k}}\right), \beta_{k}\left(\overline{v_{k}}\right)\right]$. Let $C$ be the matrix described above, constructed by stacking equalities of the form of equation (12), for all bidder types $k$ and all pairs of observed bidder sets, $\mathbb{B}$ and $\mathbb{B}^{a}$. Then if enough variation in bidder sets is observed so that $\operatorname{rank}(C) \geq L$, the externality parameters $\alpha$ are identified.

Proof. Assume that $\alpha$ is not identified in that there is some $\widetilde{\alpha} \neq \alpha^{*}$ such that $G(\cdot \mid \widetilde{\alpha}, \mathbb{B})=G\left(\cdot \mid \alpha^{*}, \mathbb{B}\right)$, for all observed bidder sets $\mathbb{B}$, where $\alpha^{*}$ is the true value of the parameter and $G$ is the observed distribution of bids. The distribution of bids can be written as:

$$
\begin{aligned}
G(\ldots, b, \ldots \mid \alpha, \mathbb{B}) & =\operatorname{Pr}\left(\ldots, b_{i_{k}} \leq b, \ldots \mid \alpha, \mathbb{B}\right) \\
& =\operatorname{Pr}\left(\ldots, \xi_{k}\left(b_{i_{k}}, G ; \alpha, \mathbb{B}\right) \leq \xi_{k}(b, G ; \alpha, \mathbb{B}), \ldots \mid \alpha, \mathbb{B}\right) \\
& =F_{\xi}\left(\ldots, \xi_{k}(b, G ; \alpha, \mathbb{B}), \ldots \mid \alpha, \mathbb{B}\right)
\end{aligned}
$$

where the second equality follows from the strict monotonicity of the inverse bid function. Function $F_{\xi}(\cdot \mid \alpha, \mathbb{B})$ is the joint distribution of the inverse bid function, conditional on externality value $\alpha$ and 
bidder set $\mathbb{B}$.

Since the distribution of bids is the same under both $\alpha^{*}$ and $\widetilde{\alpha}$, this implies that:

$$
\begin{gathered}
F_{\xi}\left(\ldots, \xi_{k}\left(b, G ; \alpha^{*}, \mathbb{B}\right), \ldots \mid \alpha^{*}, \mathbb{B}\right)=F_{\xi}\left(\ldots, \xi_{k}(b, G ; \widetilde{\alpha}, \mathbb{B}), \ldots \mid \widetilde{\alpha}, \mathbb{B}\right) \\
\Rightarrow F_{\xi_{k}}\left(\xi_{k}\left(b, G ; \alpha^{*}, \mathbb{B}\right) \mid \alpha^{*}, \mathbb{B}\right)=F_{\xi_{k}}\left(\xi_{k}(b, G ; \widetilde{\alpha}, \mathbb{B}) \mid \widetilde{\alpha}, \mathbb{B}\right)
\end{gathered}
$$

Then because of the equilibrium argument from section 3 that $\xi_{k}$ is the true inverse bidding function for a bidder of type $k$ given the true value of the externality parameter, I can say that $\xi_{k}\left(b_{i_{k}}, G ; \alpha^{*}, \mathbb{B}\right)=$ $v_{i_{k}}$. Thus $F_{\xi}\left(\ldots, \xi_{k}\left(b, G ; \alpha^{*}, \mathbb{B}\right), \ldots \mid \alpha^{*}, \mathbb{B}\right)=F_{v}\left(\ldots, \xi_{k}\left(b, G ; \alpha^{*}, \mathbb{B}\right), \ldots \mid \mathbb{B}\right)$, where $F_{v}(\cdot \mid \mathbb{B})$ is the joint distribution of valuations given bidder set $\mathbb{B}$. This also implies that the marginal distributions are equal, or that $F_{\xi_{k}}\left(\xi_{k}\left(b, G ; \alpha^{*}, \mathbb{B}\right) \mid \alpha^{*}, \mathbb{B}\right)=F_{k}\left(\xi_{k}\left(b, G ; \alpha^{*}, \mathbb{B}\right) \mid \mathbb{B}\right)$.

Since by assumption bidder participation is exogenous, then for any alternative bidder set, $\mathbb{B}^{a}$ :

$$
\begin{aligned}
F_{k}(\cdot \mid \mathbb{B}) & =F_{k}\left(\cdot \mid \mathbb{B}^{a}\right) \\
\Leftrightarrow F_{\xi_{k}}\left(\xi_{k}\left(b, G ; \alpha^{*}, \mathbb{B}\right) \mid \alpha^{*}, \mathbb{B}\right) & =F_{\xi_{k}}\left(\xi_{k}\left(b, G^{a} ; \alpha^{*}, \mathbb{B}^{a}\right) \mid \alpha^{*}, \mathbb{B}^{a}\right) \\
\Leftrightarrow F_{\xi_{k}}\left(\xi_{k}(b, G ; \widetilde{\alpha}, \mathbb{B}) \mid \widetilde{\alpha}, \mathbb{B}\right) & =F_{\xi_{k}}\left(\xi_{k}\left(b, G^{a} ; \widetilde{\alpha}, \mathbb{B}^{a}\right) \mid \widetilde{\alpha}, \mathbb{B}^{a}\right)
\end{aligned}
$$

Yet the rank condition on the matrix $C$ implies there is at most one solution to all the equalities of the same type as equation (23), for all bidder types $k$ and all the observed bidder sets. And since the equalities necessarily hold at $\alpha^{*}$, then this implies that $\widetilde{\alpha}=\alpha^{*}$, or that the externality parameter is identified.

\section{B.3 Proof of Proposition 2: Consistency of the KS Estimator}

Assume $\mathbb{A}$ is a compact subset of $\mathbb{R}^{L}$. Assume that $\xi_{k}(b, G ; \alpha, \mathbb{B})$ is the equilibrium inverse bid function for a bidder of type $k$, that is strictly increasing in $b$ and continuous in $\alpha$. Also assume that the identification conditions from section 3.1 hold. Then the estimator $\widehat{\alpha}^{K S}$ defined in section 3.2.2 is a consistent estimate for the true parameter value $\alpha^{*}$.

Consistency of this estimator requires showing that the conditions for the consistency of an extremum estimator hold. To do so I need to show that the above sample objective function converges to an objective function that is continuous in $\alpha$ and is uniquely minimized at the true parameter value $\alpha^{*}$. Assume for now that there is only one bidder type and only two observed bidder sets, $\mathbb{B}, \mathbb{B}^{a}$, that differ in the number of bidders. Allowing for more than one bidder type and more observed bidder 
sets is just a straightforward extension of this case. The sample objective function is then:

$$
\max _{v \in[\underline{\xi(\alpha)}, \overline{\bar{\xi}(\alpha)}]}\left|\widehat{F_{\mathbb{B}}}(v ; \alpha)-\widehat{F_{\mathbb{B}^{a}}}(v ; \alpha)\right|
$$

Taking one distribution at a time:

$$
\begin{aligned}
\widehat{F_{\mathbb{B}}}(v ; \alpha) & =\frac{1}{T_{\mathbb{B}}} \sum_{t=1}^{T} \frac{1}{n^{t}} \sum_{i=1}^{n^{t}} \mathbf{1}\left\{\widehat{v_{\mathbb{B}}^{i t}}(\alpha) \leq v\right\} \mathbf{1}\left\{\mathbb{B}^{t}=\mathbb{B}\right\} \\
& =\frac{1}{T_{\mathbb{B}}} \sum_{t=1}^{T} \frac{1}{n^{t}} \sum_{i=1}^{n^{t}} \mathbf{1}\left\{\xi\left(b^{i t}, G ; \alpha, \mathbb{B}\right) \leq v\right\} \mathbf{1}\left\{\mathbb{B}^{t}=\mathbb{B}\right\} \\
& \stackrel{p}{\rightarrow} \operatorname{Pr}\left(\xi\left(b^{i}, G ; \alpha, \mathbb{B}\right) \leq v \mid \mathbb{B}\right) \\
& =F_{\xi}(v \mid \mathbb{B})
\end{aligned}
$$

where the probability in equation (34) is with respect to the randomness of bids, $b^{i}$. The distribution $F_{\xi}(\cdot)$ depends on $\alpha$ in that $\xi$ is a continuous function of $\alpha$.

Similarly $\widehat{F_{\mathbb{B}^{a}}}(v ; \alpha) \stackrel{p}{\rightarrow} F_{\xi^{a}}\left(v \mid \mathbb{B}^{a}\right)$, where $F_{\xi^{a}}$ is the distribution of inverse bids for auctions with bidder set $\mathbb{B}^{a}$. Thus the sample objective function converges in probability to the objective function:

$$
\max _{v \in[\underline{\xi}(\alpha), \bar{\xi}(\alpha)]}\left|F_{\xi}(v \mid \mathbb{B})-F_{\xi^{a}}\left(v \mid, \mathbb{B}^{a}\right)\right|
$$

Again the distributions depend on $\alpha$ through $\xi$ and $\xi^{a}$, which are continuous functions of $\alpha$.

As was demonstrated in the identification section, this objective function is uniquely minimized at the true parameter value $\alpha^{*}$. Additionally, due to the continuity of $\xi(\cdot)$ with respect to $\alpha$, it can be shown that the above objective function is also continuous in $\alpha$. Thus the conditions for the consistency of an extremum estimator are met and $\widehat{\alpha}^{K S}$ is a consistent estimate for the externality parameter:

$$
\widehat{\alpha}^{K S} \stackrel{p}{\rightarrow} \alpha^{*}
$$

As stated above, showing consistency with more than one bidder type and multiple observed bidder sets, is just a straightforward extension of this case with one bidder type and two observed bidder sets.

\section{B.4 Proof of Equation (32)}

A proof of equation (32) similar to that of Brendstrup and Paarsch (2003) is given below to show where this equation comes from. 
Proof. Following the proof in Brendstrup and Paarsch (2003) we get:

$$
\begin{aligned}
& G_{k}^{w}(b \mid \mathbb{B})=\operatorname{Pr}\left(b_{i_{k}} \leq b, b_{i_{k}} \geq b_{j} \forall j \in \mathbb{B} \mid \mathbb{B}\right) \\
& =\int_{-\infty}^{b} \prod_{j \neq i_{k}} G_{j}(s \mid \mathbb{B}) \partial G_{k}(s \mid \mathbb{B}) \\
& =\int_{-\infty}^{b} \frac{\prod_{j} G_{j}(s \mid \mathbb{B})}{G_{k}(s \mid \mathbb{B})} \partial G_{k}(s \mid \mathbb{B}) \\
& =\int_{-\infty}^{b} \frac{\sum_{j} G_{j}^{w}(s \mid \mathbb{B})}{G_{k}(s \mid \mathbb{B})} \partial G_{k}(s \mid \mathbb{B}) \\
& =\int_{-\infty}^{b} \sum_{j} G_{j}^{w}(s \mid \mathbb{B}) \partial \log G_{k}(s \mid \mathbb{B}) \\
& \Longrightarrow \partial G_{k}^{w}(b \mid \mathbb{B})=\sum_{j} G_{j}^{w}(b \mid \mathbb{B}) \partial \log G_{k}(b \mid \mathbb{B}) \\
& \Longrightarrow \partial \log G_{k}(b \mid \mathbb{B})=\frac{\partial G_{w}^{k}(b \mid \mathbb{B})}{\sum_{j} G_{j}^{w}(b \mid \mathbb{B})} \\
& \Longrightarrow G_{k}(b \mid \mathbb{B})=\exp \left\{\int_{-\infty}^{b} \frac{1}{\sum_{j} G_{j}^{w}(s \mid \mathbb{B})} \mathrm{d} G_{k}^{w}(s \mid \mathbb{B})\right\}
\end{aligned}
$$

